\title{
Parâmetros urbanísticos e o conforto térmico de cânions urbanos: 0 exemplo de Campinas, SP
}

\author{
Urban legislation and thermal comfort in urban street \\ canyons: a case study in Campinas
}

\section{Lígia Parreira Muniz-Gäal \\ Cláudia Cotrim Pezzuto \\ Marcius Fabius Henriques de Carvalho \\ Lia Toledo Moreira Mota}

\section{Resumo}

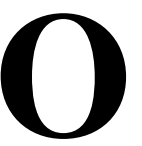

s parâmetros construtivos das legislações de uso e ocupação do solo regulam a ocupação do território urbano, e as modificações que neles ocorrem impactam no clima das cidades. Buscando analisar como a legislação de uso e ocupação do solo interfere no microclima e no conforto térmico do pedestre, um cânion urbano da cidade de Campinas foi estudado por meio de simulações computacionais feitas no programa ENVI-met 4.0 preview. Foram propostos 48 cenários estabelecidos a partir da variação da taxa de ocupação, coeficiente de aproveitamento e orientação do cânion, e comparou-se o conforto térmico proporcionado por cada cenário através do índice PET (Physiological Equivalent Temperature). Os resultados mostraram que cenários com maior relação entre altura e largura do cânion (H/W maior do que $1,0)$ apresentam temperatura do ar máxima até $1,0^{\circ} \mathrm{C}$ mais baixa que cenários mais abertos (H/W igual a 0,4$)$. O aumento da relação $\mathrm{H} / \mathrm{W}$ amplia o sombreamento do cânion e reduz a variação da sensação de conforto diária. Com relação à orientação do cânion, verificou-se que aqueles orientados paralelamente à direção predominante dos ventos têm o potencial de resfriamento das superfícies intensificado pelo aumento de sua velocidade. Enfatiza-se a importância de relacionar parâmetros urbanísticos com o clima e o conforto térmico do pedestre.

Palavras-chaves: Cânion urbano. Geometria urbana. Parâmetros urbanísticos. Conforto térmico urbano. Microclima.

Lígia Parreira Muniz-Gäal Pontifícia Universidade Católica de Campinas Campinas - SP - Brasil

Cláudia Cotrim Pezzuto Pontifícia Universidade Católica de Campinas Campinas - SP - Brasil

Marcius Fabius Hemriques de Carvalho Pontifícia Universidade Católica de Campinas Campinas - SP - Brasil

Lia Toledo Moreira Mota Pontifícia Universidade Católica de Campinas Campinas - SP - Brasil

Recebido em 07/03/17 Aceito em 22/06/17

\section{Abstract}

The constructive parameters of the legislation on land use and occupancy regulate the occupancy of urban land. Different specifications for these parameters affect the climate of cities. In order to analyse how the legislation on land use and occupancy affects the microclimate and the thermal comfort of pedestrians, this study focused on an urban canyon in the city of Campinas through the use of computer simulations made in the ENVI-met 4.0 preview program. Forty-eight scenarios based on the occupancy rate variations, the floor area rate and canyon orientation were compared regarding thermal comfort by using the PET (Physiological Equivalent Temperature) index. The results showed that scenarios with a higher correlation between canyon height and width (H/W greater than 1.0) had a maximum air temperature up to $1.0^{\circ} \mathrm{C}$ lower than more open scenarios ( $H / W$ equal to 0.4$)$. An increase in the $H / W$ ratio increased the shading of the canyon, reducing the variation of the daily comfort sensation and the peak values of the PET. Regarding the orientation of the canyon, it was verified that those oriented parallel to the predominant direction of the winds have the potential for cooling surfaces intensified by increasing their speed. The results emphasize the importance of relating urban parameters with the climate and thermal comfort of pedestrians.

Keywords: Urban canyon. Urban geometry. Urban legislation. Urban thermal comfort. Microclimate. 


\section{Introdução}

O crescimento populacional é um dos indutores de todo o ciclo de modificações no clima urbano, pois leva ao adensamento e à verticalização das áreas urbanas já dotadas de infraestrutura instalada, o que afeta ainda mais as condições climáticas. O aumento da altura das edificações gera sombreamentos, reduz o acesso solar, aumenta a absorção de ondas longas e modifica o comportamento do vento devido aos obstáculos em que se configuram as construções (KLEEREKOPER; VAN ESCH; SALCEDO, 2012).

A legislação de uso e ocupação do solo já prevê alguns parâmetros construtivos que limitam e regulam a ocupação do solo, e até estipulam taxa mínima de permeabilidade em alguns casos. No entanto, esses parâmetros pouco se baseiam em estudos climáticos e projeções de seus impactos no microclima local, levando muitas vezes a propostas que não auxiliam na preservação das condições climáticas adequadas, regulando somente a ocupação ordenada do solo.

Todavia, o comportamento climático local tem sido amplamente estudado em associação com aspectos relacionados ao cânion urbano. Cânions urbanos são definidos como configurações geométricas de vias que se localizam entre edificações que se elevam em ambos os lados, se assemelhando a um cânion natural (NICHOLSON, 1975; ALITOUDERT; MAYER, 2006; STRØMANNANDERSEN; SATTRUP, 2011).

O microclima do cânion urbano é afetado por diversos fatores, como materiais de superfície, orientação, geometria e presença de vegetação. Os materiais de superfície regulam a quantidade de radiação solar absorvida, refletida e emitida por suas superfícies (ALCHAPAR et al., 2016). A orientação determina o acesso solar e a velocidade do vento no cânion (ABREU-HARBICH; LABAKI; MATZARAKIS, 2014). A geometria, dada a relação entre a altura média das edificações e a largura da via (relação H/W), modifica o fator de visão do céu e, portanto, o acesso solar (VARDOULAKIS et al., 2003, NAKATA-OSAKI; SOUZA; RODRIGUES, 2016, MUNIZ; PEZZUTO, 2016). A presença de vegetação altera os parâmetros climáticos de temperatura e umidade relativa do ar (MINELLA; HONJO; KRÜGER, 2012; PEZZUTO et al., 2015; ALCHAPAR et al., 2016; MINELLA; KRÜGER, 2017).

Estudos como o de Johansson (2006) e Bourbia e Boucheriba (2010) mostraram que o aumento da relação H/W do cânion proporciona diminuição da temperatura do ar e da temperatura superficial, além de melhorar o conforto térmico na escala do pedestre. Já Shishegar (2013) e Achour-Younsi e Kharrat (2016) verificaram que, além do efeito da relação $\mathrm{H} / \mathrm{W}$, a orientação da via impacta sobre a quantidade de radiação solar no cânion e em sua distribuição sobre as superfícies, modificando também a velocidade do vento, que é menor em cânions rasos e com orientação perpendicular à direção predominante dos ventos. Herrington e Vittum (1977) já destacavam a velocidade do vento como um dos fatores predominantes na formação da sensação de conforto térmico. Emmanuel e Johansson (2006) encontraram uma diferença de temperatura de $7^{\circ} \mathrm{C}$ quando do aumento da relação $\mathrm{H} / \mathrm{W}(0,1 ; 0,3 ; 0,5 ; 0,8$ e 1,2$)$ no clima quente e úmido de Colombo, Sri Lanka. Krüger, Pearlmutter e Rasia (2010) mostraram que o sombreamento mútuo nas paredes leste e oeste é a principal razão da redução da temperatura do ar durante o dia em cânions orientados a N-S.

Entretanto, Burton, Bambrick e Friel (2015) evidenciaram que os planejadores urbanos estão cientes das alterações climáticas e dos potenciais impactos que elas terão sobre a saúde humana, mas que, devido à compreensão limitada de sua relação com o ambiente construído, os impactos não estão sendo planejados. Os autores ainda relatam que os agentes do planejamento urbano enfrentam conflitos durante a tomada de decisões e acabam por atribuir à saúde uma prioridade mais baixa em relação às outras áreas, como o aproveitamento do solo e a mobilidade urbana, e concluem que a incorporação da saúde e mudanças climáticas no planejamento urbano é fundamental para a adaptação do ser humano e que deve existir como uma estratégia articulada para melhorar a vida das populações urbanas.

Considerando a realidade brasileira, Gomes e Lamberts (2009), ao estudar áreas densamente ocupadas, relataram a existência de uma lacuna nas recomendações urbanísticas no que tange à incorporação de questões ambientais. Duarte e Serra (2003) propuseram um indicador urbanístico relacionando densidade construída, arborização e superfícies de água em áreas urbanizadas e enfatizaram a importância de equilibrar maior densidade construída com os elementos naturais para melhorar as condições de conforto no espaço construído.

Assim, esta pesquisa propôs analisar como a legislação de uso e ocupação do solo interfere no microclima e nas condições de conforto térmico do pedestre em um cânion urbano da cidade de Campinas, SP, visando contribuir para que os 
fatores relativos à legislação urbanística sejam tratados de forma mais adequada ao clima.

\section{Metodologia}

A metodologia deste estudo está dividida nos seguintes procedimentos: seleção da área de estudo, descrição do monitoramento microclimático nas condições de verão e inverno, descrição dos parâmetros de simulação computacional no programa ENVI-met 4.0 preview, detalhamento dos cenários propostos e dos procedimentos de avaliação do conforto térmico do pedestre e análise das variáveis ambientais.

\section{Área de estudo}

Este estudo desenvolveu-se no bairro Cambuí, localizado na cidade de Campinas, no interior do Estado de São Paulo, a 100 km da capital, em uma altitude média de $680 \mathrm{~m}$ em relação ao nível do mar e situado nas coordenadas geográficas 22053'20" Sul e $47^{\circ} 04^{\prime} 40^{\prime \prime}$ Oeste. Detentora de uma área total de $796,4 \mathrm{~km}^{2}$, dos quais $49 \%$ conformam a área urbana do município, Campinas é a sede da importante Região Metropolitana de Campinas (RMC) (PREFEITURA..., 2016).

O município é caracterizado como de clima tropical de altitude (Cwa, segundo classificação de Köppen), com verão quente e úmido e inverno ameno e seco, temperatura média anual de $22,4{ }^{\circ} \mathrm{C}$, índice pluviométrico médio de aproximadamente 1.424,5 mm anuais, umidade do ar média anual de $47 \%$ e ventos predominantes de sudeste (CENTRO..., 2016).

O bairro Cambuí se formou juntamente com a cidade, tendo como características predominantes o uso do solo misto e o intenso processo de verticalização. $\mathrm{O}$ bairro apresenta um gabarito diversificado com edificações de $7 \mathrm{~m}$ a $60 \mathrm{~m}$ de altura, conforme foi constatado em análise de campo efetuada em 2015, período de realização da pesquisa.

A área de estudo é predominantemente de uso misto, porém tem permissão de uso residencial verticalizado de acordo com a Lei de Uso e Ocupação do Solo de Campinas, Lei $n^{\circ}$ 6.031, DE 29 de dezembro de 1988 (PREFEITURA..., 2011).

A fim de estudar as possibilidades previstas na legislação de uso e ocupação do solo vigentes no bairro Cambuí e seu impacto no microclima local e no conforto térmico do pedestre, foi selecionado um recorte urbano em uma região de baixa densidade e com possibilidades de adensamento e verticalização (Figura 1, poligonal em preto). O recorte de estudo apresenta menor densidade construída, quando comparada com o restante do bairro, com predominância de edifícios de baixa altura, até $7 \mathrm{~m}$, baixa relação $\mathrm{H} / \mathrm{W}$ do cânion $(0,23)$ e baixo fator de visão do céu $(\mathrm{FVC}=0,324)$ devido à vegetação (Figura 1, destaque em amarelo).

Figura 1 - Bairro Cambuí (poligonal em preto). Recorte de estudo (destaque em amarelo)

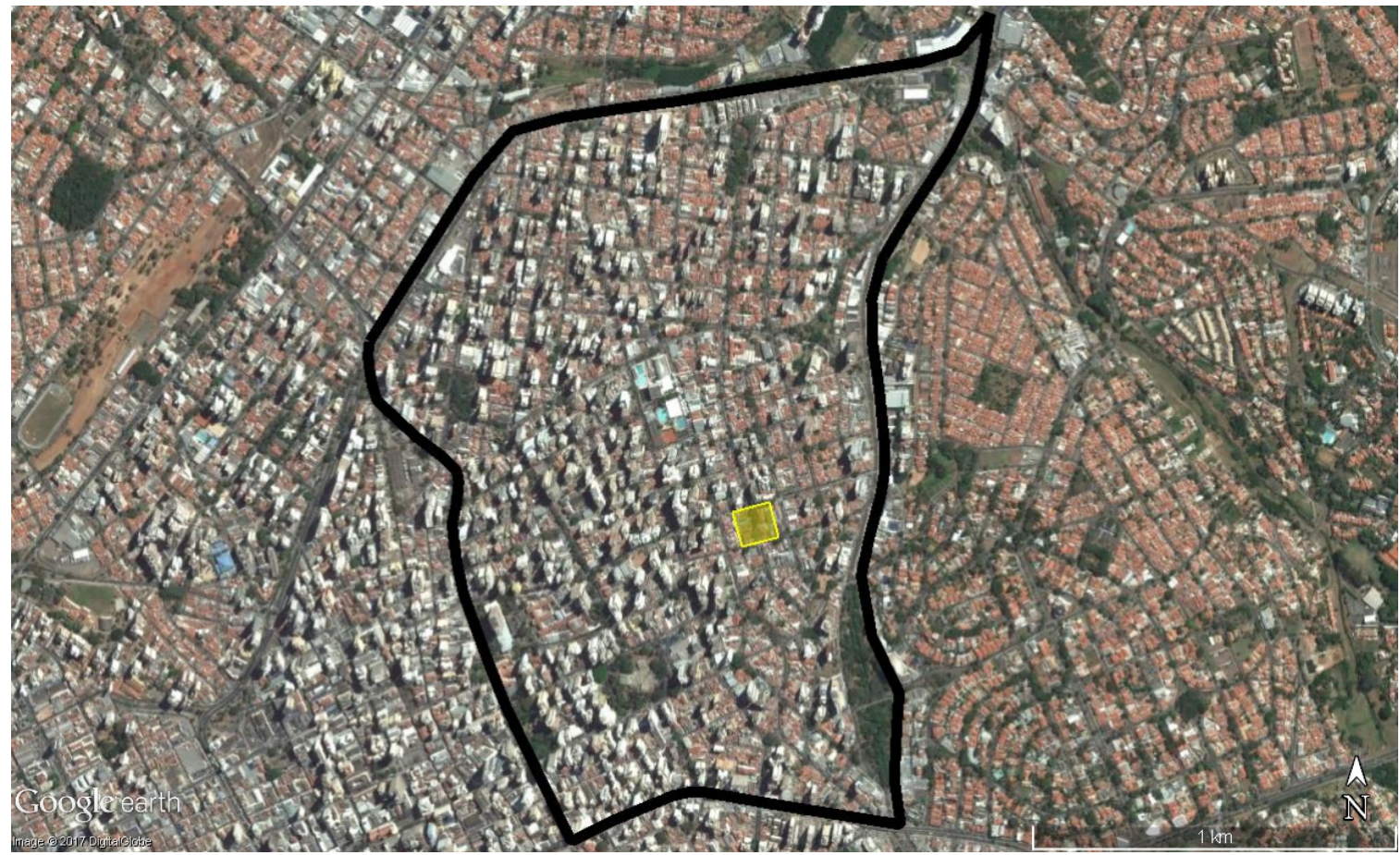

Fonte: adaptada Google Earth (2017). 
A área de estudo contempla um recorte de $104 \mathrm{~m} \times$ 104 m e um cânion central com orientação NO-SE. A coleta de dados de campo foi feita a partir de visitas in loco e digitalização de fotografia aérea. $\mathrm{O}$ cânion de estudo apresenta vias com largura de 8,0 $\mathrm{m}$, os passeios possuem 3,0 $\mathrm{m}$ de largura, e os lotes apresentam recuo frontal de 4,0 m (Figuras 2 e 3). Aproximadamente $44 \%$ do cânion é vegetado. $\mathrm{Na}$ área de estudo aproximadamente $70 \%$ dos telhados são cerâmicos, $13 \%$ metálicos, $9 \%$ lajes de concreto e $4 \%$ outros materiais. As calçadas apresentam $83 \%$ de pedra calcária e $17 \%$ de concreto. A via central é de asfalto, e as superfícies verticais têm pinturas variadas.

\section{Coleta de dados microclimáticos}

Com a finalidade de aferir os dados simulados, foi realizado o monitoramento de variáveis ambientais no interior do cânion de estudo. As variáveis monitoradas foram temperatura e umidade relativa do ar. A coleta de dados microclimáticos foi realizada nos meses de agosto a setembro de 2015, período de inverno, e de dezembro de 2015 a março de 2016, período de verão. A partir de análises estatísticas e considerando que o programa ENVImet somente simula um dia de medição, foi selecionado um dia estável e representativo de cada período, sendo o dia 21/08/2015 utilizado para o período de inverno, e o dia 07/01/2016, para o verão. Esses dois dias foram selecionados porque apresentaram proximidade com as características das normais climatológicas da cidade, conforme descrito a seguir.

Figura 2 - Recorte de estudo

Fonte: adaptada de Google Earth (2017).

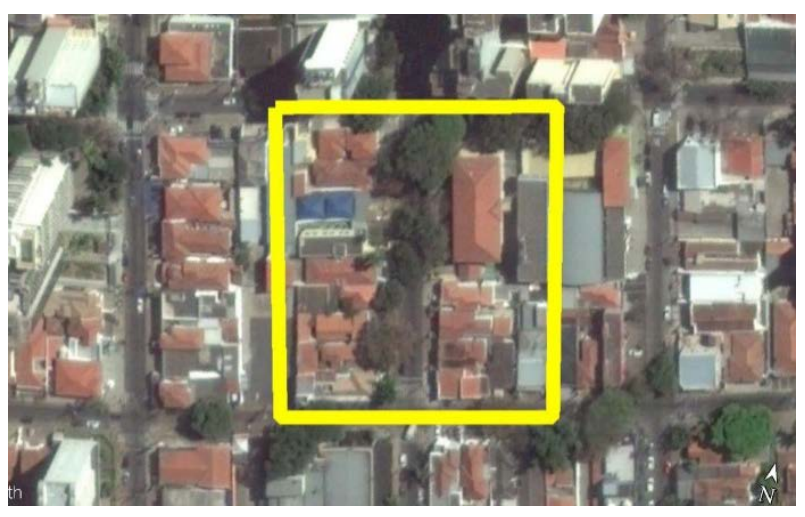

Figura 3 - Vista do cânion de estudo

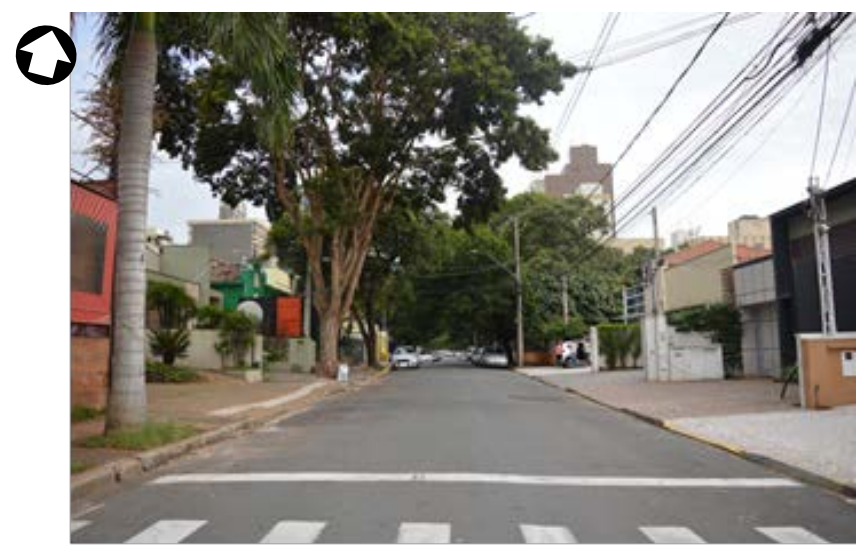

Fonte: adaptada de Google Earth (2017). 
O dia 21/08/2015 apresentou temperatura do ar máxima de $28,3{ }^{\circ} \mathrm{C}$ e mínima de $15,7{ }^{\circ} \mathrm{C}$, temperatura do ar média de $20,3{ }^{\circ} \mathrm{C}$, umidade relativa do ar de $32,0 \%$ às $15 \mathrm{~h}$, e máxima radiação solar global na estação de referência do Instituto Agronômico de Campinas (IAC) de 698,5 W/m². O dia 07/01/2016 apresentou temperatura do ar máxima de $32,7{ }^{\circ} \mathrm{C}$ e mínima de $21,7{ }^{\circ} \mathrm{C}$, temperatura do ar média de $27,6{ }^{\circ} \mathrm{C}$, umidade relativa do ar de $46,0 \%$ às 15 h e máxima radiação solar global na estação IAC de $859,6 \mathrm{~W} / \mathrm{m}^{2}$. As condições de céu, durante o período de aquecimento, para os dois dias de medições, variaram entre 3 e 4 oitavos (60\% de céu claro) e entre 5 e 7 oitavos (37\% de céu claro) (INSTITUTO..., 2017). A partir das normais climatológicas (CENTRO..., 2016), o mês de agosto apresenta uma temperatura do ar máxima de $27,0{ }^{\circ} \mathrm{C}$ e mínima de $13,8{ }^{\circ} \mathrm{C}$, temperatura do ar média de $20,5^{\circ} \mathrm{C}$ e umidade relativa do ar às $15 \mathrm{~h}$ de $36,0 \%$, e o mês de janeiro com temperatura do ar máxima de $29,9{ }^{\circ} \mathrm{C}$ e mínima de $19,8{ }^{\circ} \mathrm{C}$, temperatura do ar média de $24,7^{\circ} \mathrm{C}$ e umidade relativa do ar às $15 \mathrm{~h}$ de $57,0 \%$.

Para a instrumentação foi utilizado um sensor da marca Testo, modelo $174 \mathrm{H}$ (precisão de $\pm 0,5^{\circ} \mathrm{C}$, 20 a $+70{ }^{\circ} \mathrm{C}$, para temperatura do ar, e de $\pm 3 \%$, 2 a $+98 \%$, para umidade relativa do ar), e registros a cada 20 min. O sensor foi alocado no interior de uma proteção da marca Hobo, modelo RS1 (Figura 4), contra intempéries e incidência da radiação solar direta, e instalado no cânion urbano, no recuo frontal de um dos lados da quadra, a uma altura de 3,5 m em relação ao solo, ficando acima da linha da cobertura, distando horizontalmente $3,5 \mathrm{~m}$ da edificação mais próxima e sobre solo impermeabilizado. A instalação e a localização da estação atenderam às recomendações da World Meteorological Organization (OKE, 2006), uma vez que ficaram dentro da camada-limite das coberturas (UCL), em intervalo de $3 \mathrm{~m}$ a $5 \mathrm{~m}$ de altura.

\section{Simulação computacional no ENVI- met}

As simulações computacionais foram executadas no programa ENVI-met 4.0 preview. O programa ENVI-met é uma ferramenta desenvolvida para estudo e previsão do microclima urbano que simula as interações entre as superfícies urbanas, vegetação e atmosfera (BRUSE; FLEER, 1998). A nova versão do ENVI-met 4.0 inclui modificações significativas em relação às versões anteriores. A principal mudança dessa nova versão 4.0 é a ferramenta simple forcing, que permite a imposição de variáveis climáticas ao longo da simulação para explicar variações temporais atmosféricas e, assim, representar melhor a evolução das variáveis meteorológicas ao longo do dia. Essa nova função permite que os usuários empreguem os dados meteorológicos medidos para forçar o modelo durante a simulação, enquanto apenas perfis climáticos relativamente simples podem ser usados nas versões anteriores do ENVI-met, tais como velocidade do vento constante e perfis idealizados para a temperatura do ar e radiação solar (YANG et al., 2013; ACERO; HERRANZ-PASCUAL, 2015). Um novo modelo de vegetação $3 \mathrm{D}$ também foi implementado no ENVI-met 4.0, em substituição ao modelo de vegetação $1 \mathrm{D}$ utilizado em versões anteriores. O modelo de vegetação 3D torna possível descrever diferentes vegetações com formas variadas e distribuição espacial das folhas. No entanto, a atenuação da radiação difusa de vegetação não é ainda levada em conta (YANG et al., 2013). Por último, o módulo de construção na versão 4.0 também leva em consideração a inércia térmica de paredes e de telhados (ACERO; HERRANZ-PASCUAL, 2015).

Figura 4 - Instrumentação instalada e detalhe da proteção
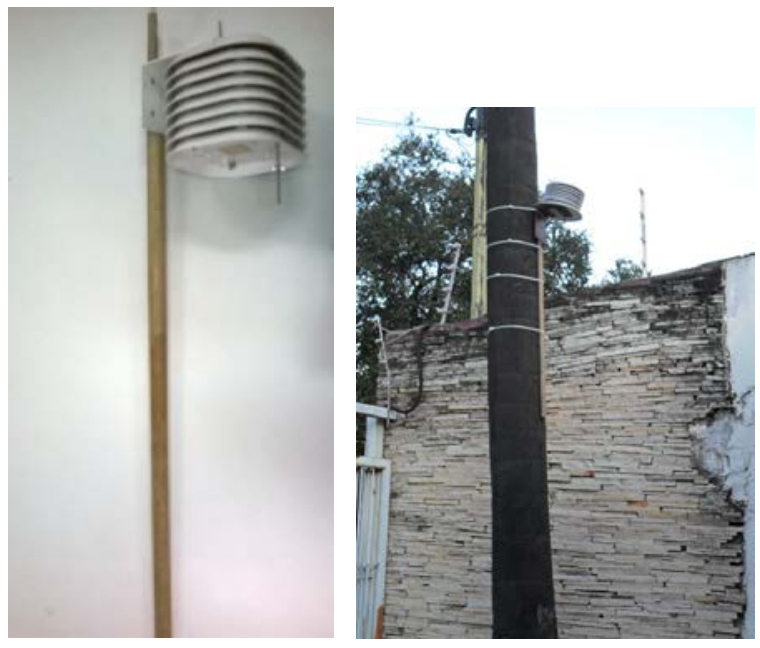
A simulação no programa ENVI-met requer dois arquivos principais: um de configuração urbana, em que é modelada a área de estudo (incluindo localização dos edifícios, vegetação, solo, superfícies e pontos de saída de dados climáticos receptores); e outro de configuração climática, que contém todos os valores de inicialização e horários. As seções a seguir descrevem o processo.

\section{Modelagem do recorte de estudo}

Para a digitalização da área no programa foi utilizada uma resolução de grid de $2 \mathrm{~m} \times 2 \mathrm{~m} \times 2 \mathrm{~m}$, totalizando uma área de $52 \times 52 \times 40$ grids, a qual corresponde à composição do recorte de estudo, de $104 \mathrm{~m} \times 104 \mathrm{~m}$.

A resolução de $2 \mathrm{~m}$ foi escolhida para manter uma boa representatividade da área. A altura total do modelo foi $40 \mathrm{~m}$, a qual se mostrou suficiente, uma vez que, segundo Gusson (2014), a altura mínima necessária é duas vezes a altura do edifício mais alto. O método de geração do grid vertical foi o equidistante (equidistant). Foram inseridos seis grids de borda (nesting grids) ao redor do modelo com o objetivo de manter a estabilidade (YANG et al., 2013). A inclinação em relação ao norte, para fins de calibração do modelo, foi $15^{\circ}$, representativa do recorte de estudo.

Para melhor representação da área real, buscou-se no banco de dados padrão do modelo as representações de vegetação que mais se assemelhavam à vegetação encontrada no recorte de estudo. Para as gramíneas foi utilizada a vegetação de 50 cm (ID:XX; Foliage Albedo: 0,2; LAD 0,30); para as árvores de médio porte foi utilizada vegetação de copa densa e altura de 12 m (ID:AJ; Foliage Albedo: 0,6; LAD 0,70); para as árvores de pequeno porte foi utilizada vegetação de $5 \mathrm{~m}$ de altura (ID:LI; Foliage Albedo: 0,4; LAD: 0,70) e palmeiras sem folhas (ID: PW; Foliage Albedo: 0,6; LAD: 0,50).

Os materiais utilizados na modelagem da área de estudo e nos cenários propostos foram baseados nos materiais default do programa ENVI-met 4.0 preview, sendo alterados os valores de albedo das superfícies externas verticais e horizontais para 0,2 e 0,3 respectivamente. Esses valores foram definidos a partir dos estudos de Sailor e Fan (2002), os quais relatam albedos médios das superfícies externas em áreas urbanas. Para as coberturas foi utilizado o tipo ID:R2 (Reflexão 0,3; Emissividade 0,9); para as paredes, o tipo ID:B1 (Reflexão 0,2; Emissividade 0,9); para as vias foi utilizado o tipo ID:ST (Reflexão 0,2; Emissividade 0,9); para as calçadas, o tipo ID:BA (Reflexão 0,3; Emissividade 0,9), para os pisos, o tipo ID:PD (Reflexão 0,2; Emissividade 0,9); e para a superfície dos solos foi utilizado o tipo ID: LO (Albedo 0,0; Emissividade 0,98). As alterações foram efetuadas para que o modelo representasse mais fielmente as características de refletância existentes na área de estudo.

Após a edição dos materiais foi feita a digitalização da área (Figura 5). Para fins de calibração do modelo, o receptor (P1) foi posicionado no mesmo local onde foi instalada a estação de medição de dados climáticos reais.

\section{Figura 5 - Área de estudo (P1 - Ponto de coleta de dados/receptor)}

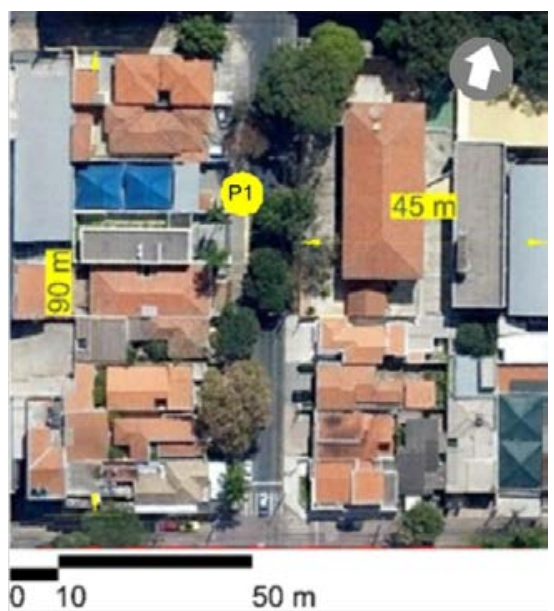

(a) Foto aérea

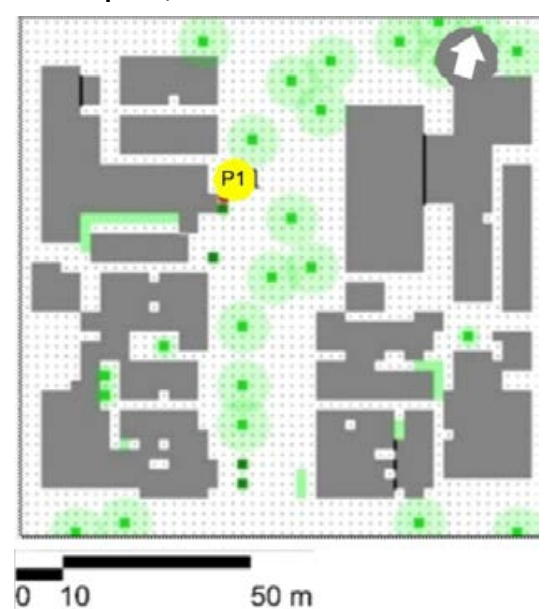

(b) Digitalização no programa ENVI-met

Fontes: (a) adaptada de Google Earth (2017) e (b) adaptada de ENVI-met. 


\section{Parâmetros de entrada da simulação}

A Tabela 1 descreve os parâmetros de entrada da configuração dos dados climáticos no programa ENVI-met para as simulações de inverno e verão. As variáveis velocidade e direção do vento na altura de $10 \mathrm{~m}$ foram obtidas da estação meteorológica urbana de referência, localizada no Instituto Agronômico de Campinas (IAC), distante aproximadamente $1,6 \mathrm{~km}$ a noroeste da área de estudo. Os dados de umidade específica do ar a $2.500 \mathrm{~m}$ foram obtidos da coleta de radiossondagem do aeroporto do Campo de Marte (Estação ${ }^{\circ}$ 83779), da Universidade de Wyoming, uma vez que é a estação mais próxima da área que coleta esse tipo de dado. Para umidade e temperatura do solo considerou-se o padrão do modelo.

Com o objetivo de ajustar a radiação solar global incidente com o valor coletado na estação do Instituto Agronômico de Campinas (IAC), foi utilizada a ferramenta solar adjust, que permite ajustar a radiação solar de ondas curtas calculada à situação estudada. Em algumas situações pode acontecer de os fluxos de energia solar estimados pelos métodos internos do ENVI-met serem sistematicamente muito altos ou muito baixos. Nesse caso, é possível ajustar esses valores de 50\% a $150 \%$ do valor calculado pelo ENVI-met, aproximando-se, assim, da situação real. Dessa forma, utilizou-se o coeficiente de ajuste solar 0,7 para o inverno e 0,9 para o verão.

Para a temperatura do ar e a umidade relativa foram utilizados os dados monitorados no cânion de estudo. A simulação foi configurada para ter início às $21 \mathrm{~h} 00$ com o objetivo de isolar a influência do aporte de radiação solar no início das simulações. Para as simulações foram considerados três dias (três ciclos), total de 76 h, e a estabilidade do modelo foi alcançada na terceira curva, a qual foi utilizada para análises. Para a variável nebulosidade foram considerados os padrões do modelo com os ajustes de valor 0 para os dados de nuvens alta, média e baixa. A simulação foi executada na versão de simulação de $100 \times 100 \times 40$ grids, a qual se mostrou suficiente para o tamanho da área modelada.

Tabela 1 - Parâmetros de entrada da simulação

\begin{tabular}{|c|c|c|}
\hline Parâmetro & Inverno & Verão \\
\hline Data da simulação & $21 / 08 / 2015$ & $07 / 01 / 2016$ \\
\hline Hora de início & 21h00 & 21h00 \\
\hline Total de horas de simulação & 76 & 76 \\
\hline Velocidade do vento a $10 \mathrm{~m}(\mathrm{~m} / \mathrm{s})^{1}$ & 4,2 & 2,4 \\
\hline Direção do vento $\left({ }^{0}\right)^{1}$ & 135 & 135 \\
\hline Temperatura $(\mathrm{K})^{2}$ & 291,1 & 300,7 \\
\hline Umidade específica (a $2.500 \mathrm{~m}-\mathrm{g} / \mathrm{kg})^{3}$ & 5,69 & 9,19 \\
\hline Umidade relativa (a $2 \mathrm{~m}-\%)^{2}$ & 70,4 & 60,7 \\
\hline Coeficiente de ajuste solar & 0,70 & 0,90 \\
\hline \multirow[t]{4}{*}{ Umidade do solo $(\%)^{4}$} & 50 & 50 \\
\hline & 60 & 60 \\
\hline & 60 & 60 \\
\hline & 60 & 60 \\
\hline \multirow[t]{4}{*}{ Temperatura do solo $(\mathrm{K})^{4}$} & 293 & 293 \\
\hline & 293 & 293 \\
\hline & 293 & 293 \\
\hline & 293 & 293 \\
\hline
\end{tabular}

Nota: Legenda:

${ }^{1}$ dados do Instituto Agronômico de Campinas;

2dados coletados no cânion urbano;

${ }^{3}$ dados do Aeroporto do Campo de Marte; e

${ }^{4}$ dados padrões do modelo. 


\section{Cenários de Estudo}

Uma vez calibrado o modelo e constatada sua representatividade em reproduzir o comportamento climático da área real, novas propostas de ocupação do solo (cenários de estudo) foram feitas para o recorte de estudo. As propostas para os cenários de estudo se basearam em aspectos da legislação urbanística. A Lei de Uso e Ocupação do Solo de Campinas, Lei $\mathrm{n}^{\circ}$ 6031, de 29 de dezembro de 1988, atualizada em 2011 (PREFEITURA..., 2011), prevê para a área de estudo os seguintes requisitos:

(a) quanto ao uso na categoria habitacional serão permitidos os usos unifamiliares e multifamiliares; e

(b) quanto à ocupação para o uso habitacional serão permitidos os tipos:

- H3 - edificações destinadas a uma única habitação por lote e suas construções acessórias; e

- HMV-1 e HMV-2 - habitações multifamiliares verticais - conjuntos de unidades habitacionais agrupadas verticalmente em um ou mais blocos.

A mesma Lei de Uso e Ocupação do Solo (PREFEITURA..., 2011) define os seguintes parâmetros construtivos: taxa de ocupação, que é a razão entre a área de projeção da edificação e a área do lote; o coeficiente de aproveitamento, que é o número que multiplica a área do lote e que, quando dividido pela área do pavimento tipo, resulta na quantidade máxima de pavimentos da edificação; e a altura máxima da edificação, que é igual à soma da largura da via e do recuo frontal do lote. Assim foram estudados os parâmetros previstos para habitações multifamiliares verticais do tipo HMV-2 e considerados os seguintes itens da legislação: (a) testada mínima (15 m);

(b) lote mínimo $\left(450 \mathrm{~m}^{2}\right)$;

(c) taxa de ocupação (TO $<0,5)$;

(d) coeficiente de aproveitamento $(\mathrm{C}=2+1,5 \times$ (0,5 - TO));

(e) altura máxima da edificação ( $\mathrm{H}=\mathrm{L}+2 \mathrm{R})$, onde $\mathrm{H}$ corresponde à altura máxima da edificação, L é a largura da via pública de circulação e R o recuo frontal; e

(f) recuos mínimos (6 m para frente e fundos e 4 $\mathrm{m}$ para as laterais).

Para os cenários foram considerados dois grupos de configuração de quadra: o primeiro grupo (cenários 1a, 1b e 1c), com três lotes de testada mínima de 30 m; e o segundo grupo (cenários 2a, 2b e 2c), com seis lotes de testada de $15 \mathrm{~m}$, todos com profundidade de $45 \mathrm{~m}$ (Figuras 6 e 7). Essa configuração foi estabelecida com a finalidade de aumentar a área construída da edificação e, consequentemente, a taxa de ocupação.

Em cada cânion foram dispostos nove receptores, três em cada lado do passeio e três no centro da via. A localização destes foi distribuída com o objetivo de abranger o possível percurso do pedestre no cânion de estudo. Para as análises foi considerado o valor médio dos nove receptores, resultando em uma curva diária, a cada 20 min, de cada variável estudada. Os dados utilizados foram referentes à terceira curva de interação e relativos a uma altura aproximada de $1,5 \mathrm{~m}$, correspondente à altura do pedestre.

\section{Figura 6 - Configuração de quadra com seis lotes (os pontos 1 a 9 são receptores)}

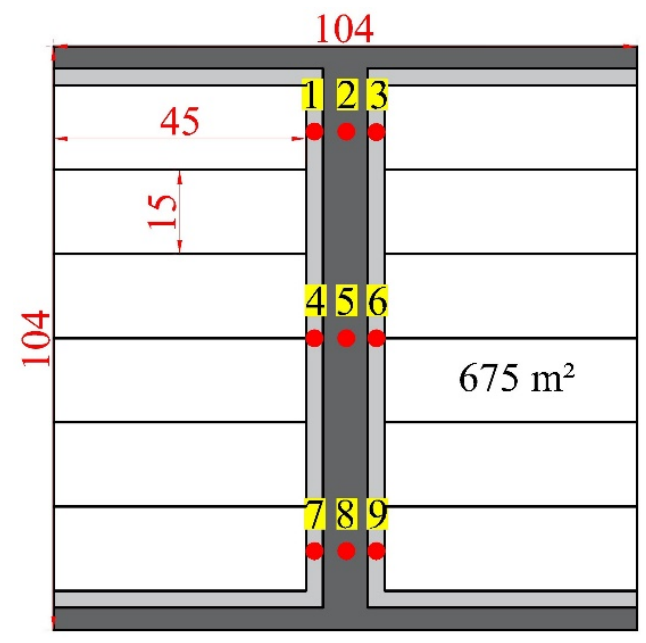


Figura 7 - Configuração de quadra com três lotes (os pontos 1 a 9 são receptores)

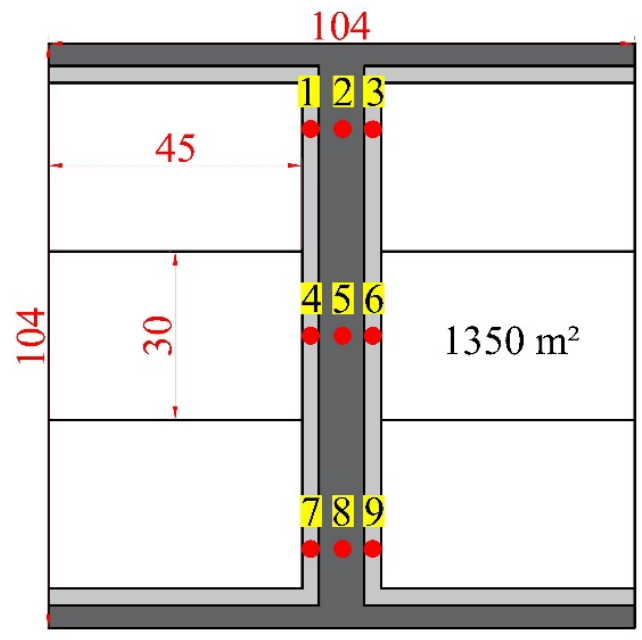

Nos cenários estudados os materiais de superfície utilizados foram os mesmos da calibração do modelo, assim como as dimensões da área modelada e a configuração dos grids. Apenas a altura do modelo foi modificada em cada cenário, correspondente ao dobro da altura da edificação mais alta em cada cenário. Para os cenários foi mantida a mesma dimensão da área $104 \mathrm{~m} \times 104 \mathrm{~m}$. Para a avaliação dos cenários a inclinação da área em relação ao norte foi considerada $0^{\circ}$ (norte-sul), e posteriormente os cenários foram avaliados nas orientações leste-oeste (L-O), nordeste-sudoeste (NE-SO) e noroeste-sudeste (NO-SE). Foi também considerado um modelo sem vegetação, porque o intuito foi avaliar apenas os aspectos construtivos, sem a interferência das trocas térmicas e evapotranspiração efetuadas pela vegetação. Objetivou-se com isso verificar a influência do sombreamento causado pelas edificações no conforto térmico dos pedestres, conforme proposto por outros autores como Krüger, Pearlmutter e Rasia (2010) e Ali-Toudert e Mayer (2006).

Assim, para o atendimento da legislação vigente na área, foram propostos os cenários 1a, 2a, 1b e $2 \mathrm{~b}$. Os cenários 3a e 3b foram propostos considerandose um aumento do coeficiente de aproveitamento para 4, aproximadamente o dobro do permitido pela legislação. Estes dois últimos cenários visam avaliar o efeito do coeficiente de aproveitamento nas condições de conforto térmico do pedestre e nas condições microclimáticas do cânion de estudo. Os recuos laterais e posterior foram mantidos mínimos, variando-se o recuo frontal apenas quando necessário. Todos os cenários tiveram como critério comum atingir a maior altura possível das edificações. A Tabela 2 apresenta as variáveis de cada cenário. A seguir descreve-se cada um deles:

(a) cenários 1a e 2a: máxima taxa de ocupação; (b) cenários 1b e 2b: mínima taxa de ocupação, considerada 0,1 ; e

(c) cenários 1c e 2c: coeficiente de aproveitamento 4 .

Os seis tipos de cenários foram simulados nas orientações norte-sul (N-S), nordeste-sudoeste (NE$\mathrm{SO})$, leste-oeste (L-O) e noroeste-sudeste (NO-SE) (Quadro 1). Dessa forma, totalizou-se um conjunto de 24 cenários, os quais, simulados nas estações de inverno e verão, resultaram em 48 cenários avaliados.

\section{Procedimentos de análise do conforto térmico e variáveis ambientais}

Para a avaliação do conforto térmico do pedestre foi utilizado o índice de conforto Temperatura Fisiológica Equivalente (PET - Physiological Equivalent Temperature, em inglês) (HOPE, 1999). O índice PET foi calculado através do programa RayMan Pro 1.2, desenvolvido pelo Meteorological Institute of Freiburg (MATZARAKIS; RUTZ; MAYER, 2016). Esse programa utiliza como parâmetros de cálculo as seguintes variáveis humanas: sexo masculino, idade de 35 anos, massa corporal de $75 \mathrm{~kg}$, altura de 1,75 m, taxa metabólica de $80 \mathrm{~W}$ e isolamento térmico da vestimenta $\left(\mathrm{I}_{\mathrm{cl}}\right)$ de 0,9 clo. Além disso, são inseridas variáveis ambientais como temperatura do ar, temperatura radiante média, velocidade do vento, umidade relativa do ar e localização geográfica, obtidos da simulação computacional. $\mathrm{O}$ índice gerado é expresso em graus Celsius $\left({ }^{\circ} \mathrm{C}\right)$.

Para as análises do PET e definição da faixa de aceitabilidade térmica foram considerados os estudos de Monteiro e Alucci (2010), que calibraram o índice PET e verificaram sua 
aplicabilidade em espaços urbanos abertos na cidade de São Paulo, SP, Brasil, chegando aos limites apresentados na Tabela 3. De acordo com o estudo, o intervalo considerado confortável (neutro) é entre $18^{\circ} \mathrm{C}$ e $26^{\circ} \mathrm{C}$.

As variáveis ambientais e humanas dos nove receptores de cada cenário, simuladas a cada 20 min, durante um ciclo de $24 \mathrm{~h}$ foram inseridas no progama RayMan Pro 1.2 juntamente com as informações de localização, resultando na variação diária do índice PET para cada um dos 48 cenários propostos. A altura de extração dos dados foi de aproximadamente $1,5 \mathrm{~m}$, correspondente ao nível do pedestre.

\section{Calibração do modelo ENVI- met}

Para calibração do modelo de simulação foi realizada a comparação entre as curvas de temperatura e umidade relativa do ar medidas e simuladas para os dois dias de estudo no período de inverno e verão (21/08/2015 e 07/01/2016). Os dados foram comparados entre o ponto monitorado no cânion urbano e o simulado no programa (P1Figura 5). Nas Tabelas 4 e 5 são apresentados os valores médios, máximos e mínimos e a amplitude obtidos nas duas situações, medida e simulada.

Para verificar a acurácia do modelo entre as séries medidas (M) e preditas (P) pelo programa ENVImet foram empregados os seguintes métodos estatísticos: coeficiente de correlação (r), raiz quadrada do erro médio (RMSE, RMSEs e RMSEu), erro médio absoluto (MAE), desvio das médias (MBE) e coeficiente de determinação $\left(\mathrm{R}^{2}\right)$, conforme a Tabela 5.

Tabela 2 - Descrição dos cenários de estudo

\begin{tabular}{|c|c|c|c|c|c|c|}
\hline \multirow[b]{2}{*}{ Parâmetros } & $\begin{array}{c}\text { Cenário } \\
\text { 1a }\end{array}$ & $\begin{array}{c}\text { Cenário } \\
\text { 1b }\end{array}$ & $\begin{array}{c}\text { Cenário } \\
\text { 1c }\end{array}$ & $\begin{array}{c}\text { Cenário } \\
\text { 2a }\end{array}$ & $\begin{array}{c}\text { Cenário } \\
\text { 2b }\end{array}$ & \multirow[t]{2}{*}{$\begin{array}{c}\text { Cenário } \\
2 \mathrm{c}\end{array}$} \\
\hline & & & & & & \\
\hline $\begin{array}{l}\text { Coeficiente } \\
\text { aproveitamento } \\
\text { (CA) }\end{array}$ & 2,02 & 2,60 & 4 & 2,24 & 2,59 & 4 \\
\hline Taxa ocupação (TO) & 0,49 & 0,10 & 0,49 & 0,34 & 0,10 & 0,34 \\
\hline Recuo frontal (m) & 9 & 33 & 9 & 6 & 29 & 6 \\
\hline $\begin{array}{l}\text { Altura total das } \\
\text { edificações - H (m) }\end{array}$ & 12 & 80 & 24 & 20 & 72 & 35 \\
\hline Área do lote $\left(\mathrm{m}^{2}\right)$ & 1.350 & 1.350 & 1.350 & 675 & 675 & 675 \\
\hline Área construída $\left(\mathrm{m}^{2}\right)$ & 660 & 132 & 660 & 231 & 70 & 231 \\
\hline Testada (m) & 30 & 30 & 30 & 15 & 15 & 15 \\
\hline $\begin{array}{l}\text { Largura do cânion - } \\
\text { W (m) }\end{array}$ & 32 & 80 & 32 & 26 & 72 & 26 \\
\hline Relação H/W & 0,4 & 1,0 & 0,8 & 0,8 & 1,0 & 1,4 \\
\hline
\end{tabular}

Nota: *pontos vermelhos representam os nove receptores.

\section{Quadro 1 - Orientações do cânion simuladas}

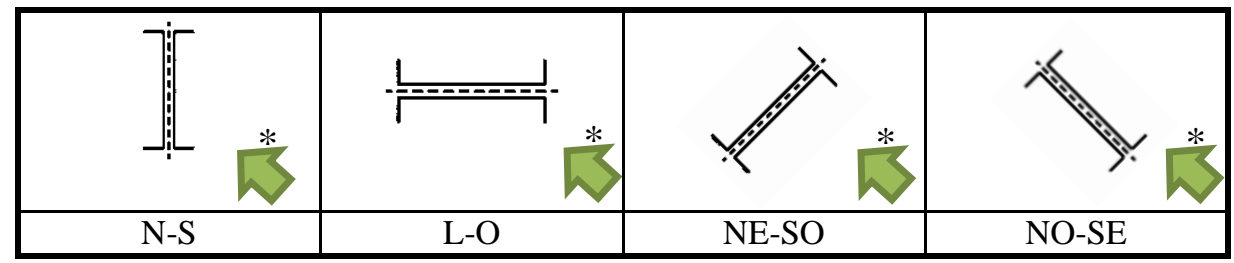

Nota: *direção dos ventos predominantes (sudeste - SE). 
Tabela 3 - Calibração do índice PET proposto para São Paulo

\begin{tabular}{c|c|c}
\hline Temperatura $\left({ }^{\circ} \mathbf{C}\right)$ & Sensação térmica & Pontuação \\
\hline$<4$ & Muito frio & -3 \\
$4-12$ & Frio & -2 \\
$12-18$ & Pouco frio & -1 \\
$18-26$ & Neutro & 0 \\
$26-31$ & Pouco calor & 1 \\
$31-43$ & Calor & 2 \\
$>43$ & Muito calor & 3 \\
\hline
\end{tabular}

Fonte: Monteiro e Alucci (2010).

Tabela 4 - Comparação dos valores médios, máximos, mínimos e amplitude para as variáveis temperatura e umidade relativa do ar

\begin{tabular}{l|l|c|c|c|c}
\hline \multirow{2}{*}{ Período } & \multirow{2}{*}{ Variável } & \multicolumn{2}{|c|}{ Temperatura $\left({ }^{\circ} \mathbf{C}\right)$} & \multicolumn{2}{c}{ Umidade (\%) } \\
\cline { 3 - 6 } & & Medida & Simulada & Medida & Simulada \\
\hline \multirow{3}{*}{ Inverno } & Mínima & 15,7 & 15,8 & 34,1 & 34,6 \\
& Média & 20,3 & 20,2 & 60,8 & 60,1 \\
& Máxima & 28,3 & 27,6 & 78,0 & 76,7 \\
& Amplitude & 12,6 & 11,9 & 43,9 & 42,1 \\
\hline \multirow{3}{*}{ Verão } & Mínima & 21,7 & 21,9 & 35,7 & 34,7 \\
& Média & 27,6 & 28,0 & 55,1 & 53,8 \\
& Máxima & 32,7 & 34,0 & 74,1 & 73,2 \\
& Amplitude & 11,0 & 12,1 & 38,4 & 38,5 \\
\hline
\end{tabular}

Tabela 5 - Indicadores de desempenho do modelo ENVI-met para o período de inverno e verão, temperatura e umidade relativa do ar

\begin{tabular}{l|c|c|c|c}
\hline \multirow{2}{*}{ Índice } & \multicolumn{2}{|c|}{ Temperatura do ar $\left({ }^{\mathbf{0}} \mathbf{C}\right)$} & \multicolumn{2}{c}{ Umidade relativa do ar (\%) } \\
\cline { 2 - 5 } & Inverno & Verão & Inverno & Verão \\
\hline RMSE & 0,2941 & 0,6994 & 1,1668 & 1,8732 \\
RMSEs & 0,2223 & 0,1194 & 2,0359 & 1,7695 \\
RMSEu & 0,4106 & 0,6252 & 2,9822 & 3,2732 \\
MBE & 0,0431 & 0,4189 & 0,7135 & 1,2894 \\
MAE & 0,2350 & 0,4811 & 0,9385 & 1,4989 \\
$\mathbf{R}^{2}$ & 0,9970 & 0,9884 & 0,9971 & 0,9902 \\
$\mathbf{r}$ & 0,9985 & 0,9942 & 0,9986 & 0,9951 \\
\hline
\end{tabular}

O RMSE, medida da magnitude média dos erros estimados, apresenta valor sempre positivo; quanto mais próximo de zero, maior a precisão da estimativa (ALVES; VECHIA, 2011; WILKS, 2006). Suas componentes, RMSEu - erro não sistemático - e RMSEs - erro sistemático -, indicam possíveis erros no desenho do modelo (WILLMOTT, 1981). De acordo com Stone (1993), pequenas quantidades de erros discrepantes podem causar um aumento significativo no RMSE. Além disso, de acordo com Chow e Brazel (2012) e Guo, Murray e Lee (2002), RMSEs próximos de zero e a proximidade entre os valores de RMSEu e RMSE indicam bom desempenho do modelo. Sendo assim, bons desempenhos foram observados tanto para a variável temperatura do ar, quanto para a umidade relativa do ar. A temperatura do ar para os períodos de inverno e verão, respectivamente, apresentou RMSE igual a $0,2941^{\circ} \mathrm{C}$ e $0,6994{ }^{\circ} \mathrm{C}$; RMSEs igual a $0,2223^{\circ} \mathrm{C}$ e $0,1194{ }^{\circ} \mathrm{C}$; e RMSEu igual a $0,4106^{\circ} \mathrm{C}$ e $0,6252^{\circ} \mathrm{C}$. A umidade relativa do ar para os períodos de inverno e verão, respectivamente, apresentou RMSE igual a 1,1668\% e 1,8732\%; RMSEs igual a $2,0359 \%$ e 1,7695\%; e RMSEu igual a 2,9822\% e $3,2732 \%$. Os coeficientes de correlação (r) e de determinação $\left(\mathrm{R}^{2}\right)$ também apresentaram bom desempenho, com valores superiores a 0,98 . Os baixos índices apresentados para MAE e MBE também evidenciam que os dados simulados estão próximos dos medidos. 


\section{Resultados}

\section{Avaliação microclimática}

\section{Avaliação da temperatura}

A Tabela 6 apresenta a temperatura do ar máxima, mínima e média e a amplitude térmica encontradas para cada um dos seis cenários (1a, 1b, 1c, 2a, 2b e 2c) e em cada uma das quatro orientações (N-S, NO-SE, L-O e NE-SO) nos períodos de inverno e verão.

No período de inverno verifica-se que as maiores diferenças foram na temperatura do ar máxima. A diferença na temperatura do ar máxima entre as orientações de um mesmo cenário variou de $0,5{ }^{\circ} \mathrm{C}$ (cenário 2c) a $1,0{ }^{\circ} \mathrm{C}$ (cenário $1 \mathrm{~b}$ e $1 \mathrm{c}$ ), sendo a orientação NO-SE a que apresentou temperatura do ar máxima mais elevada (em todos os tipos de cenário).
O cenário 1a $(\mathrm{TO}=0,49, \mathrm{CA}=2,02$ e $\mathrm{H} / \mathrm{W}=0,4)$ apresentou amplitude térmica maior que os demais cenários, $12,2{ }^{\circ} \mathrm{C}$, para a orientação NO-SE. Observa-se que esse cenário apresenta temperatura mínima similar à dos demais cenários, mas apresenta temperatura máxima maior, daí a maior amplitude verificada para esse cenário. O cenário $1 \mathrm{a}$ atinge uma diferença máxima de $2,4{ }^{\circ} \mathrm{C}$ quando em comparação com o cenário 2c ( $\mathrm{TO}=0,34, \mathrm{CA}=4,00$ e $\mathrm{H} / \mathrm{W}=1,4)$, que apresentou temperatura do ar máxima de $25,7^{\circ} \mathrm{C}$ e menor amplitude térmica em relação aos demais cenários, $9,2{ }^{\circ} \mathrm{C}$. Esse comportamento se justifica pelo acesso solar dos cânions, que varia conforme a relação H/W. Quanto maior a relação entre a altura e a largura do cânion, menor seu acesso solar e maior o sombreamento das superfícies no cânion, reduzindo a temperatura do ar máxima; tal comportamento também varia com a orientação dele.

Tabela 6 - Temperatura do ar máxima, média e mínima e amplitude térmica nos seis cenários e nas quatro orientações. Períodos de inverno e verão

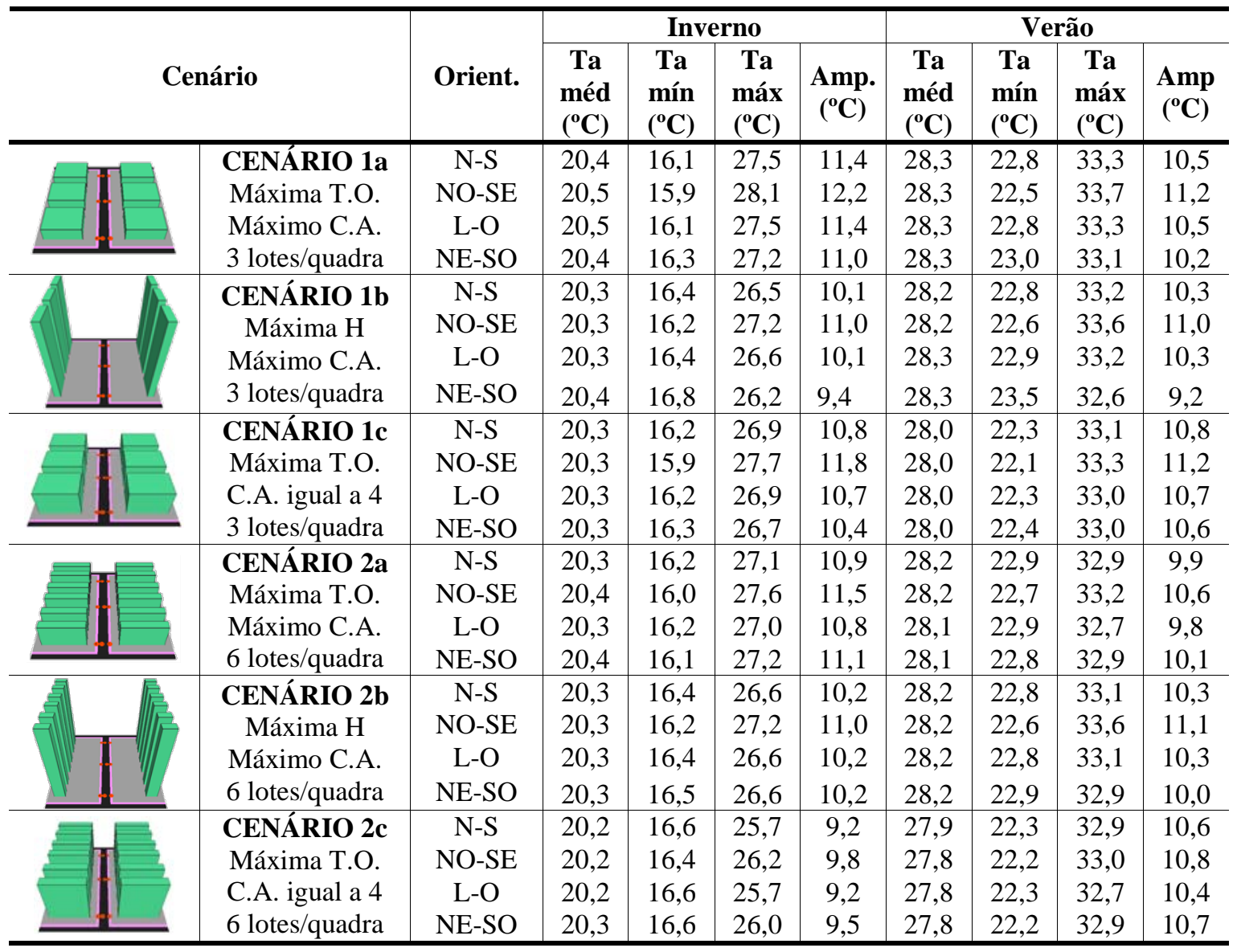


Tais resultados corroboram os encontrados por Emmanuel e Johansson (2006), que verificaram redução de aproximadamente $3,5^{\circ} \mathrm{C}$ na temperatura do ar máxima quando a relação $\mathrm{H} / \mathrm{W}$ foi reduzida de 1,2 para 0,1 , e por Alchapar et al. (2016), que observaram redução de aproximadamente $3,0^{\circ} \mathrm{C}$ na temperatura do ar máxima quando a relação H/W foi reduzida de 1,5 para 0,2. Ali-Toudert e Mayer (2006) também encontraram uma redução de $3,0^{\circ} \mathrm{C}$ na temperatura do ar máxima quando da redução da relação H/W de 4,0 para 0,5.

Considerando os cenários com seis lotes por quadra, tanto a redução da taxa de ocupação para 0,1 (cenário 2a e 2b) quanto o aumento do coeficiente de aproveitamento de aproximadamente 2 para 4 (cenários 2a e 2c) proporcionaram redução significativa na temperatura do ar máxima. Entre os cenários $2 \mathrm{a}(\mathrm{TO}=0,34)$ e $2 \mathrm{~b}(\mathrm{TO}=0,1)$, verificou-se redução na temperatura do ar máxima de $0,4{ }^{\circ} \mathrm{C}$ a $0,6{ }^{\circ} \mathrm{C}$ (dependendo da orientação do cânion). Entre os cenários 2a $(\mathrm{CA}=1)$ e 2c $(\mathrm{CA}=4)$, verificou-se redução na temperatura do ar máxima entre $0,4{ }^{\circ} \mathrm{C}$ e $0,6^{\circ} \mathrm{C}$ (dependendo da orientação do cânion).

Nos cenários com três lotes por quadra (1a, 1b e 1c), a redução na temperatura do ar máxima entre os cenários 1a e 1b, onde a taxa de ocupação foi reduzida de 0,49 para 0,1 , foi de $0,9{ }^{\circ} \mathrm{C}$ a $1,0{ }^{\circ} \mathrm{C}$ (dependendo da orientação do cânion). Já entre os cenários 1a e 1c, onde o coeficiente de aproveitamento foi aumentado de 2 para 4, verificou-se redução na temperatura do ar máxima entre $0,4{ }^{\circ} \mathrm{C}$ e $0,6{ }^{\circ} \mathrm{C}$ (dependendo da orientação do cânion).

Entre os cenários estudados, um aumento de 52 m na altura das edificações do cenário $2 \mathrm{~b}$ em relação às do cenário 2a provocou redução de $0,6{ }^{\circ} \mathrm{C}$ na temperatura do ar máxima, enquanto um aumento de apenas $15 \mathrm{~m}$ na altura das edificações do cenário 2a em relação às edificações do cenário 2c provocou redução de $1,2{ }^{\circ} \mathrm{C}$. Isso ocorre porque, quando se aumenta o coeficiente de aproveitamento, permitese uma altura $(\mathrm{H})$ maior para uma mesma largura (W) do cânion, elevando a relação H/W. Por outro lado, se o aumento da altura da edificação estiver condicionado a uma redução da taxa de ocupação por meio do aumento do recuo frontal do lote, a altura (H) e a largura (W) do cânion serão aumentadas simultaneamente, o que provocará alteração menos significativa na relação $\mathrm{H} / \mathrm{W}$ do que no primeiro caso.

No período de verão, verifica-se que a diferença na temperatura do ar máxima entre as orientações de um mesmo cenário variou de $0,1{ }^{\circ} \mathrm{C}$ (cenário 2c) a $1,0^{\circ} \mathrm{C}$ (cenário $1 b$ ), sendo a orientação NO-SE a que apresentou temperatura do ar máxima mais elevada em todos os tipos de cenário, inclusive no inverno. No entanto, diferentemente do que foi observado no período de inverno, a amplitude térmica é mais homogênea entre os cenários no período de verão, diferentemente do que foi observado no período de inverno, mas é sempre maior na orientação NO-SE, e a temperatura mínima também é mais baixa nessa orientação.

As alterações na temperatura do ar máxima evidenciadas pelo aumento do coeficiente de aproveitamento para 4 ou pela redução da taxa de ocupação para 0,1 também foram menos expressivas no período de verão, tendo sido observada variação máxima de $0,4{ }^{\circ} \mathrm{C}$.

A Figura 8 mostra a variação da temperatura do ar durante o ciclo de um dia para cada cenário nos períodos de inverno e verão. Destaca-se que o cenário 1a $(\mathrm{TO}=0,49, \quad \mathrm{CA}=2,02$ e $\mathrm{H} / \mathrm{W}=0,4)$ apresenta a maior amplitude térmica no período de inverno. No período de verão o cenário 1c ( $\mathrm{TO}=0,49, \mathrm{CA}=4,00$ e $\mathrm{H} / \mathrm{W}=0,8)$ apresenta maior amplitude térmica por alcançar temperatura mínima mais baixa. Além disso, em ambos os períodos, inverno e verão, a orientação NO-SE proporciona maior amplitude térmica, maior máxima e menor mínima.

\section{Avaliação da velocidade do vento}

A Figura 1 mostra a variação da velocidade do vento nos cânions no nível do pedestre $(1,5 \mathrm{~m})$. A diferença de velocidade do vento entre um mesmo tipo de cenário orientado a N-S e L-O foi muito pequena, da ordem de $0,1 \mathrm{~m} / \mathrm{s}$ a $0,4 \mathrm{~m} / \mathrm{s}$, tanto no período de inverno quanto no de verão.

A orientação NO-SE, paralela à direção predominante dos ventos (SE), proporciona velocidade do vento mais alta para todos os cenários, ao mesmo tempo em que cenários orientados de forma perpendicular à direção predominante dos ventos, NE-SO, apresentam velocidade do vento reduzida, pois a disposição das edificações forma uma barreira para a passagem do vento. Krüger, Pearlmutter e Rasia (2010) também verificaram que há maior velocidade do vento em cânions orientados na direção predominante dos ventos e que a orientação perpendicular é menos favorável por formar zonas virtuais de estagnação nas faces das edificações e dificultar seu resfriamento. 
Figura 8 - Variação da temperatura do ar em cada cenário nos períodos de inverno e verão

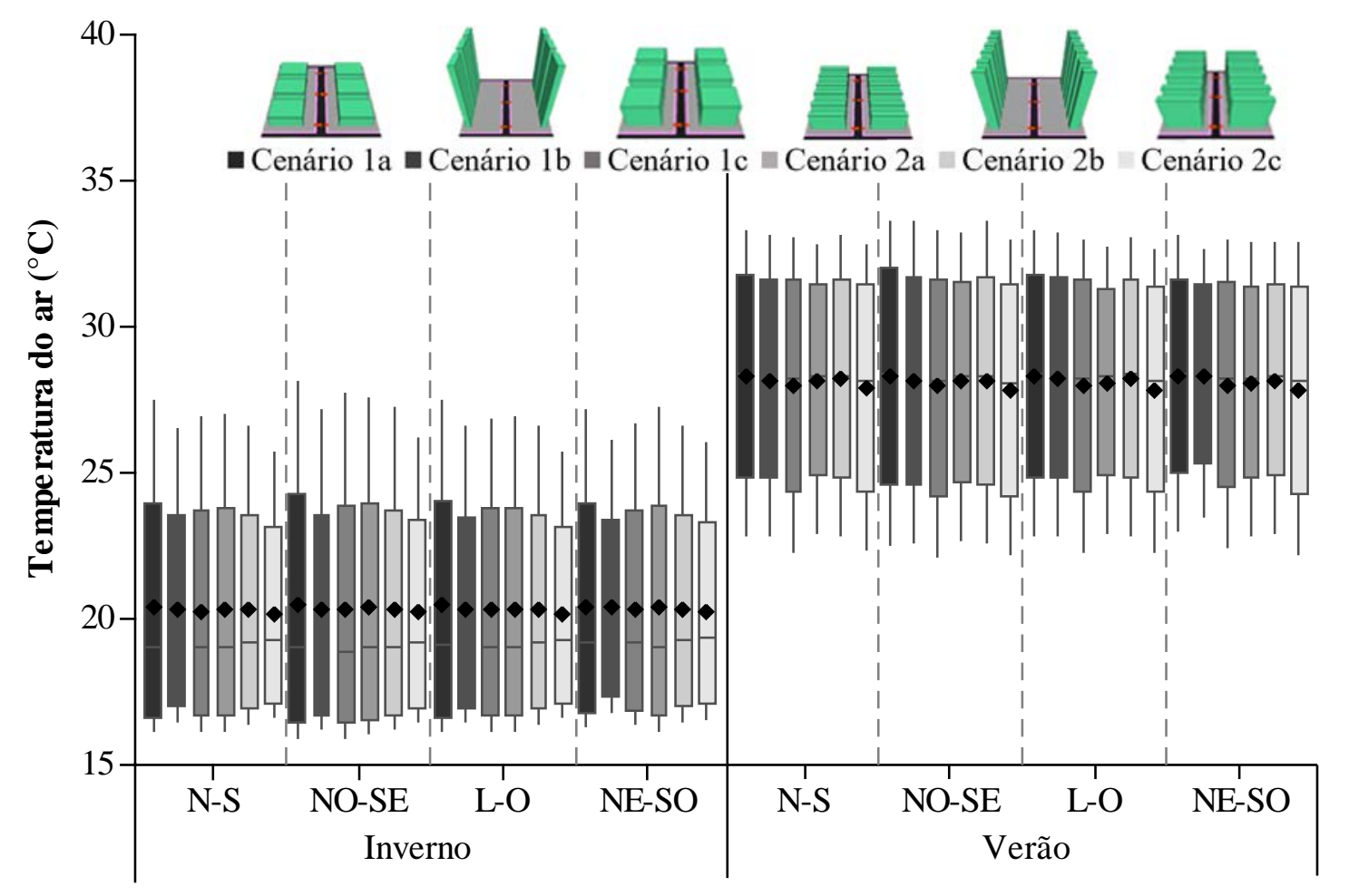

Figura 9 - Velocidade do vento a 1,5 m em cada cenário

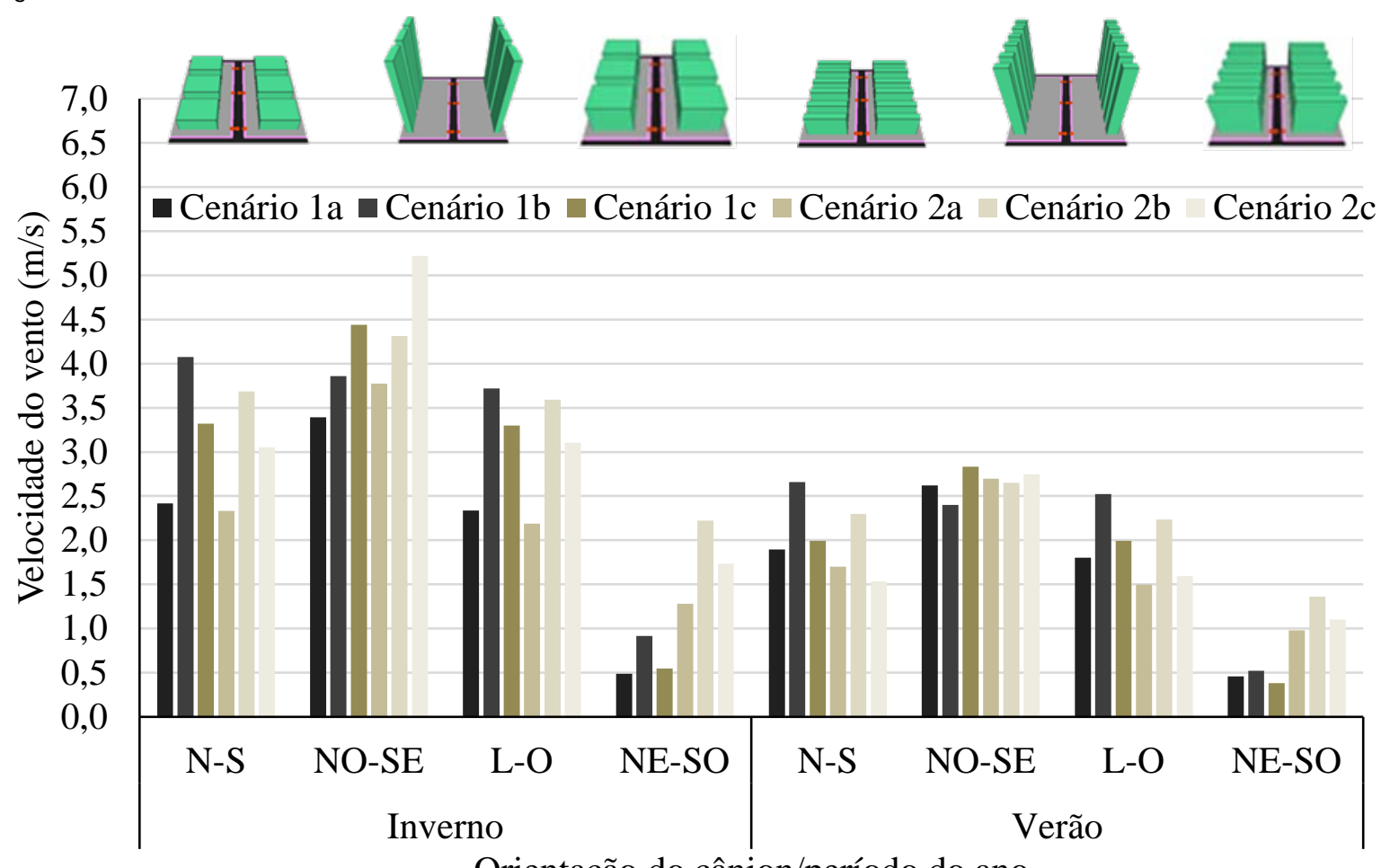

Orientação do cânion/período do ano 
Entretanto, verifica-se que, para a orientação NESO dos cenários 2a, 2b e 2c, onde há maior permeabilidade do vento devido à maior quantidade de recuos entre as edificações (quadra com seis lotes), a velocidade do vento é mais alta do que nos cenários 1a, 1b e 1c (quadra com três lotes), atingindo uma diferença máxima de $1,7 \mathrm{~m} / \mathrm{s}$ no período de inverno e de $1,0 \mathrm{~m} / \mathrm{s}$ no verão.

Conforme a Tabela 7 , a redução da taxa de ocupação acarretou aumento na velocidade do vento no cânion, exceto naqueles orientados na direção predominante dos ventos (NO-SE). No grupo dos cenários de seis lotes por quadra (cenários 2a, 2b e 2c), a redução da taxa de ocupação de 0,34 (cenários 2a e 2c) para 0,1 (cenário 2b) proporcionou aumento na velocidade do vento do cenário $2 \mathrm{~b}$ de até $1,4 \mathrm{~m} / \mathrm{s}$. No grupo de cenários de três lotes por quadra (cenários 1a, 1b e 1c), a redução da taxa de ocupação de 0,49 (cenários 1a e 1c) para 0,1 (cenário 1b) proporcionou aumento na velocidade do vento do cenário 4 de até $1,7 \mathrm{~m} / \mathrm{s}$.

Segundo Herrington e Vittum (1977), a modificação da velocidade do vento interfere significativamente nas condições de conforto do ambiente urbano. Os cenários com menor taxa de ocupação possuem um cânion mais largo e edifícios mais altos, o que favorece a canalização e potencializa a velocidade do vento, podendo, assim, diminuir a sensação de desconforto nos períodos mais quentes do dia.

Relacionando os dados de temperatura do ar com os de velocidade do vento, nota-se que os cenários na orientação NO-SE, paralela à direção predominante dos ventos, apresentaram temperatura do ar mínima mais baixa, o que contribui para a maior amplitude térmica observada nessa orientação. Isso ocorre porque a velocidade do vento nessa orientação é mais elevada, contribuindo para um maior resfriamento das superfícies do cânion e, assim, para a redução das temperaturas mínimas.

\section{Avaliação do conforto térmico}

Nesta seção foi feita uma análise comparativa dos 48 cenários de estudo, período de inverno e verão, a partir da avaliação do conforto térmico humano, através do índice PET. Para o cálculo do índice PET foi considerada a curva diária média dos nove receptores de saída. A Figura 10 apresenta a variação diária do índice PET para cada cenário nas quatro orientações propostas. Para as análises foi considerada a faixa de aceitabilidade térmica proposta por Monteiro e Alucci (2010), com limites inferior e superior de $18{ }^{\circ} \mathrm{C}$ e $26{ }^{\circ} \mathrm{C}$ (linhas tracejadas em vermelho).

Nos períodos de inverno e verão, verifica-se que a orientação NE-SO é a que proporciona valores de pico de PET mais elevados. Para o período de inverno, nota-se ainda que, nesta mesma orientação, mais de $25 \%$ do dia ( $3^{\circ}$ quartil) encontra-se acima do limite de conforto para o calor $\left(26^{\circ} \mathrm{C}\right)$, exceto no cenário 2c.

No período de verão cerca de $50 \%$ do dia (mediana) manteve-se abaixo do limite de conforto para o calor $\left(26^{\circ} \mathrm{C}\right)$, independentemente da orientação ou do tipo de cenário. Todavia, a orientação NE-SO continuou se mostrando mais crítica, com valores de pico mais altos, sendo ainda observada redução significativa quando o cânion é orientado a NO-SE.

Tabela 7 - Velocidade do vento média $(\mathrm{m} / \mathrm{s})$ nos cenários de estudo e diferença de velocidade do vento (d - $\mathrm{m} / \mathrm{s}$ ) observada pela redução da taxa de ocupação dos lotes

\begin{tabular}{|c|c|c|c|c|c|c|c|c|c|c|c|}
\hline & & \multicolumn{5}{|c|}{ SEIS LOTES/QUADRA } & \multicolumn{5}{|c|}{ TRÊS LOTES/QUADRA } \\
\hline \multicolumn{2}{|c|}{ Cenário } & $2 a$ & 2c & $2 b$ & \multirow{2}{*}{$d_{2 b-2 a}$} & \multirow{2}{*}{$d_{2 b-2 c}$} & $1 \mathrm{a}$ & 1c & $1 \mathrm{~b}$ & \multirow{2}{*}{$\mathrm{d}_{1 \mathrm{~b}-1 \mathrm{a}}$} & \multirow{2}{*}{$d_{1 b-1 c}$} \\
\hline & T.O. & 0,34 & 0,34 & 0,1 & & & 0,49 & 0,49 & 0,1 & & \\
\hline \multirow{4}{*}{ 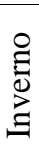 } & N-S & 2,3 & 3,1 & 3,7 & $+1,4$ & $+0,6$ & 2,4 & 3,3 & 4,1 & $+1,7$ & $+0,8$ \\
\hline & NO-SE & 3,8 & 5,2 & 4,3 & $+0,5$ & $-0,9$ & 3,4 & 4,4 & 3,9 & $+0,5$ & $-0,6$ \\
\hline & $\mathrm{L}-\mathrm{O}$ & 2,2 & 3,1 & 3,6 & $+1,4$ & $+0,5$ & 2,3 & 3,3 & 3,7 & $+1,4$ & $+0,4$ \\
\hline & NE-SO & 1,3 & 1,7 & 2,2 & $+0,9$ & $+0,5$ & 0,5 & 0,5 & 0,9 & $+0,4$ & $+0,4$ \\
\hline \multirow{4}{*}{ } & N-S & 1,7 & 1,5 & 2,3 & $+0,6$ & $+0,8$ & 1,9 & 2,0 & 2,7 & $+0,8$ & $+0,7$ \\
\hline & NO-SE & 2,7 & 2,7 & 2,7 & 0,0 & $-0,1$ & 2,6 & 2,8 & 2,4 & $-0,2$ & $-0,4$ \\
\hline & $\mathrm{L}-\mathrm{O}$ & 1,5 & 1,6 & 2,2 & $+0,7$ & $+0,6$ & 1,8 & 2,0 & 2,5 & $+0,7$ & $+0,5$ \\
\hline & NE-SO & 1,0 & 1,1 & 1,4 & $+0,4$ & $+0,3$ & 0,5 & 0,4 & 0,5 & $+0,1$ & $+0,1$ \\
\hline
\end{tabular}


Figura 10 - Variação do índice PET durante o dia nos 48 cenários e intervalo de conforto

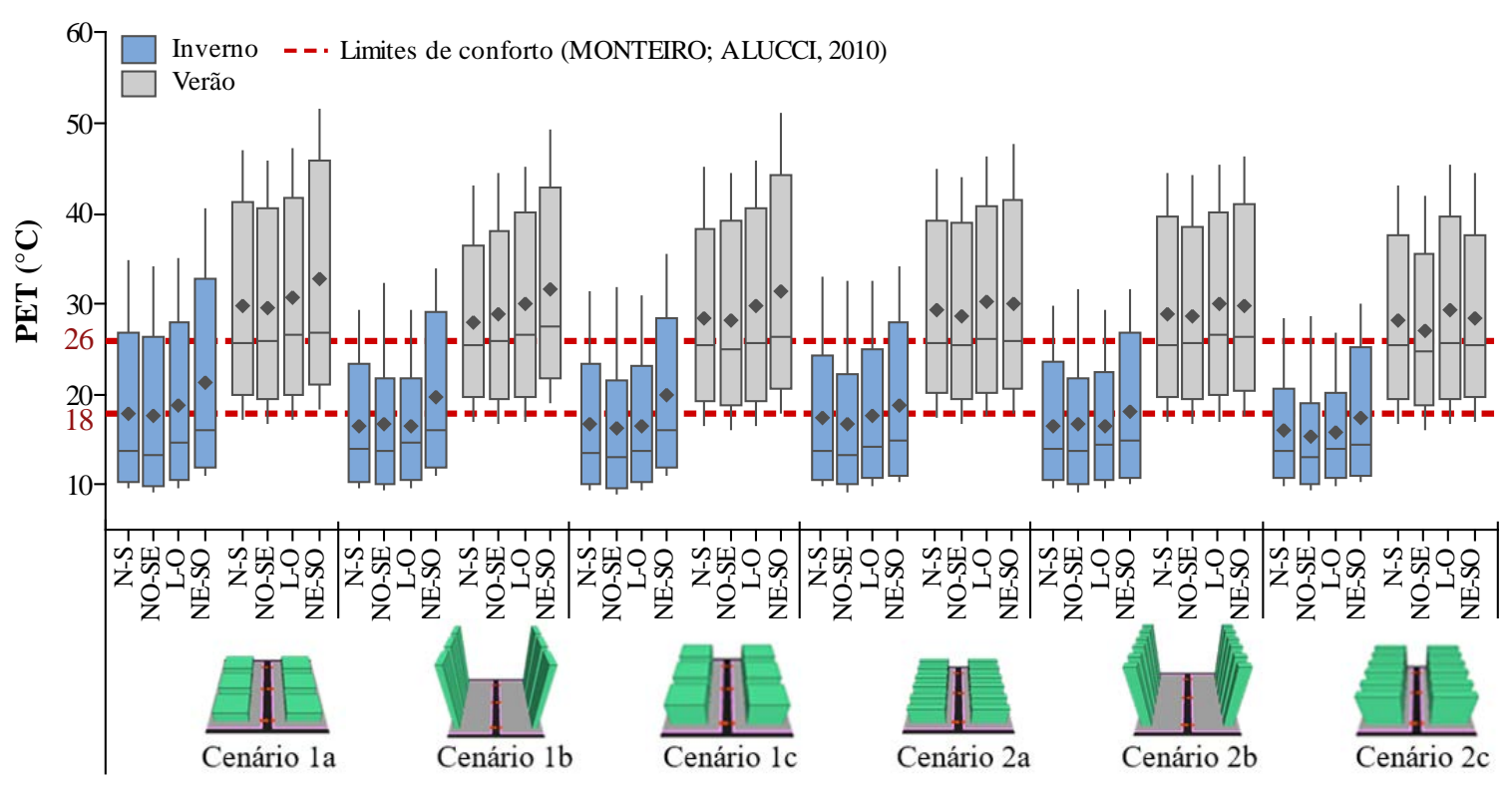

A orientação NE-SO proporciona maior bloqueio do vento por parte das edificações, uma vez que as edificações dispostas de forma perpendicular à direção predominante dos ventos dificultam a ventilação do cânion e possíveis trocas térmicas por convecção, elevando os valores de PET. Os cenários orientados a NO-SE, que se encontram na direção predominante dos ventos, apresentaram índice PET mais baixo devido ao maior potencial de resfriamento das superfícies como consequência da maior velocidade do vento. Tais observações foram também verificadas nos dados climáticos de temperatura do ar, em que a temperatura mínima mais baixa foi obtida nos cenários orientados a NOSE devido ao maior resfriamento proporcionado pela velocidade do vento mais alta.

O cenário 1a $(\mathrm{TO}=0,49, \mathrm{CA}=2,02$ e $\mathrm{H} / \mathrm{W}=0,4)$ mostrou-se mais desconfortável que os demais cenários em todas as orientações tanto no período de inverno quanto no de verão, alcançando os piores índices tanto para o frio quanto para o calor. Por outro lado, nos cenários de maior relação $\mathrm{H} / \mathrm{W}$ (cenários 1b, 2b e 2c) ocorreu diminuição da variação do índice durante o dia e redução significativa no valor de pico do PET em todas as orientações.

$\mathrm{Na}$ orientação L-O, em que o efeito do sombreamento das edificações é menor, percebeuse mais claramente o efeito da relação $\mathrm{H} / \mathrm{W}$ sobre o PET, que tem seu pico reduzido com o aumento da relação $\mathrm{H} / \mathrm{W}$. A relação entre o H/W e o PET foi também constatada no período de verão, porém de forma mais discreta, reforçando os resultados obtidos no período de inverno. Esses resultados corroboram os obtidos por Emmanuel, Rosenlund e Johansson (2007), Ali-Toudert e Mayer (2006) e Johansson e Emmanuel (2006), que evidenciam a relação entre a geometria do cânion $(\mathrm{H} / \mathrm{W})$ e o conforto térmico (PET).

De acordo com a Figura 11, no período de inverno o cenário 2c $(\mathrm{TO}=0,34, \mathrm{CA}=4,00$ e $\mathrm{H} / \mathrm{W}=1,4)$ proporcionou maior porcentagem de conforto, principalmente na orientação L-O (31\%). O cenário 1b $(\mathrm{TO}=0,10, \mathrm{C}=2,60$ e $\mathrm{H} / \mathrm{W}=1,4)$ e o cenário $2 \mathrm{~b}$ ( $\mathrm{TO}=0,10, \mathrm{CA}=2,59$ e $\mathrm{H} / \mathrm{W} 1,0)$ apresentaram porcentagem de desconforto para o calor reduzida e pouco aumento na porcentagem de conforto. No período de verão a porcentagem de desconforto para o calor é muito similar entre os cenários, havendo destaque para os cenários 1a e 1b na orientação NESO, onde não foi observado desconforto para o frio.

Constata-se que o aumento do coeficiente de aproveitamento de aproximadamente 2 para 4 proporcionou melhorias mais significativas no conforto térmico do cânion urbano do que a redução da taxa de ocupação para 0,1 , uma vez que os cenários 1c e 2c $(\mathrm{CA}=4)$ apresentaram maior porcentagem de conforto e menor porcentagem de desconforto para o calor do que os cenários $1 \mathrm{~b}$ e $2 \mathrm{~b}$ $(\mathrm{TO}=0,1)$ respectivamente. Isso se deve ao fato de o aumento do coeficiente de aproveitamento acarretar uma relação H/W maior do que a redução no coeficiente de aproveitamento. 
Figura 11 - Porcentagem de conforto durante o dia

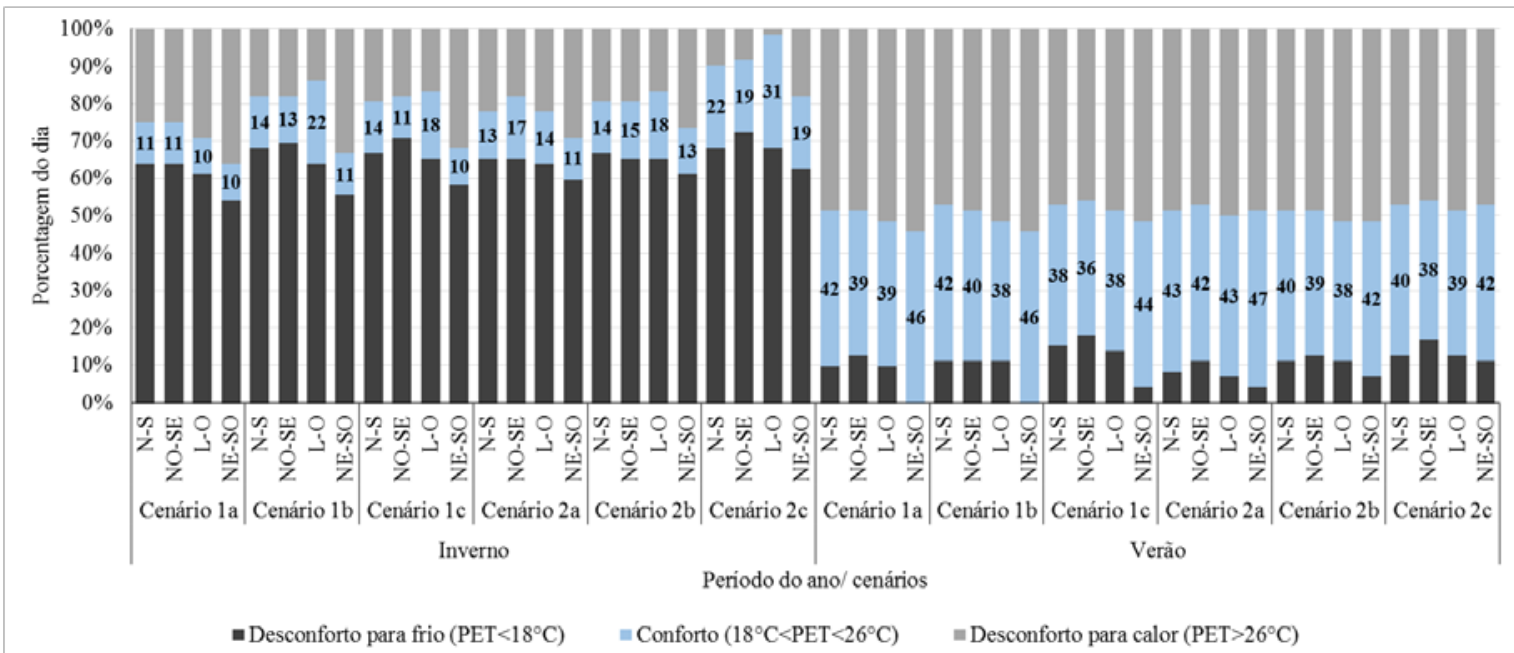

\section{Considerações finais}

Os resultados deste estudo demonstraram uma relação direta do conforto térmico dos pedestres com a configuração geométrica do cânion urbano. Tanto a relação H/W quanto a orientação do cânion tiveram influência considerável no ambiente térmico e, consequentemente, na sensação térmica dos pedestres. A análise conjunta dos parâmetros urbanísticos, taxa de ocupação e coeficiente de aproveitamento, com a relação $\mathrm{H} / \mathrm{W}$, variável comumente utilizada em estudos de conforto urbano, contribuiu para um melhor entendimento das condições microclimáticas do cânion em estudo. As simulações demonstraram que o sombreamento proporcionado pelas edificações é uma estratégia de mitigação do estresse térmico para espaços abertos.

$\mathrm{O}$ aumento da relação H/W ampliou o sombreamento proporcionado pelas edificações nas superfícies do cânion, o que reduziu a variação da sensação de conforto durante o dia e diminuiu os valores de pico do PET, melhorando, assim, o conforto térmico no nível do pedestre, principalmente no período de verão. Além disso, essa estratégia também proporcionou redução na temperatura do ar máxima. Em relação a esse comportamento destaca-se que os parâmetros construtivos coeficiente de aproveitamento e taxa de ocupação, por estarem diretamente relacionados com a relação $\mathrm{H} / \mathrm{W}$, interferem indiretamente no conforto térmico.

Além disso, os resultados evidenciaram que, nos cenários com maior altura das edificações e recuo frontal mínimo, ou seja, maior coeficiente de aproveitamento, o aumento da sensação de conforto térmico foi mais sensível do que naqueles onde houve aumento da altura das edificações e maior recuo frontal, ou seja, menor taxa de ocupação. Diante disso, infere-se que o coeficiente de aproveitamento impacta mais significativamente no conforto térmico no nível do pedestre.

Ressalta-se que, apesar de os cenários com maior recuo frontal (menor taxa de ocupação) apresentarem conforto térmico ligeiramente reduzido em relação aos de menor recuo frontal (maior taxa de ocupação), aqueles apresentaram maior permeabilidade aos ventos. Isso indica que o sombreamento das edificações, ocasionado pela altura e proximidade entre elas, impacta mais significativamente no conforto térmico dos pedestres do que uma condição de maior ventilação do cânion.

Ademais, a orientação também se mostrou determinante do conforto térmico. Tal fator modifica tanto o acesso solar do cânion, e sua condição de sombreamento, quanto a velocidade do vento nele. Entre os cenários estudados verificou-se que a orientação paralela à direção predominante dos ventos potencializa sua velocidade, o que favorece a redução da sensação de desconforto no verão.

Embora não tenha sido o foco desta pesquisa, a vegetação é um dispositivo que pode potencializar o conforto térmico do cânion urbano por proporcionar, entre outras funções e benefícios, o sombreamento. Em situações de baixa relação H/W o uso da vegetação no cânion é recurso favorável para o melhoramento do clima e a diminuição do estresse térmico. Assim sendo, essas duas estratégias, vegetação e aumento da relação H/W, devem ser criteriosamente utilizadas, conjugadas ou não, dependendo de cada situação.

A proposta deste artigo foi discutir a capacidade de resposta climática das formas urbanas através da 
configuração geométrica dos cânions, relacionadas com os parâmetros da legislação urbanística. No entanto, essas soluções diferem dependendo da região de estudo.

Finalmente, ressalta-se a importância de relacionar os parâmetros urbanísticos com o conforto térmico do pedestre, pois isso propicia melhor tomada de decisão para os planejadores urbanos. Enfatiza-se, no entanto, que as estratégias aqui abordadas se mostraram benéficas no que diz respeito ao conforto térmico apenas ao nível do pedestre no interior do cânion urbano. Por esse motivo são indicados estudos futuros que considerem o conforto do pedestre de maneira integrada ao interior das quadras e ao ambiente interno das edificações.

\section{Referências}

ABREU-HARBICH, L. V.; LABAKI, L. C.; MATZARAKIS, A. Thermal Bioclimate in Idealized Urban Street Canyons in Campinas, Brazil. Theoretical and Applied Climatology, v. 115, p. 333-340, 2014.

ACERO, J. A.; HERRANZ-PASCUAL, K. A Comparison of Thermal Comfort Conditions in Four Urban Spaces by Means of Measurements and Modelling Techniques. Building and Environment, v. 93, p. 245-257, nov. 2015.

ACHOUR-YOUNSI, S.; KHARRAT, F. Outdoor Thermal Comfort: impact of the geometry of an urban street canyon in a Mediterranean Subtropical Climate: case study Tunis, Tunisia. Procedia Social and Behavioral Sciences, v. 216, p. 689700, jan. 2016.

ALCHAPAR, N. L. et al. The Impact of Different Cooling Strategies on Urban air Temperatures: the cases of Campinas, Brazil, and Mendoza, Argentina. Theoretical and Applied

Climatology, v. 130, n. 1/2, p. 35-50, 2016.

ALI-TOUDERT, F.; MAYER, H. Numerical Study on the Effects of Aspect Ratio and Orientation of an Urban Street Canyon on Outdoor Thermal Comfort in Hot and Dry Climate.

Building and Environment, v. 41, n. 2, p. 94-108, Feb. 2006.

ALVES, E. D. L.; VECCHIA, F. A. S. Análise de Diferentes Métodos de Interpolação Para a Precipitação Pluvial no Estado de Goiás. Acta Scientiarum - Human and Social Sciences, v. 33, n. 2, p. 193-197, 2011.

BOURBIA, F.; BOUCHERIBA, F. Impact of Street Design on Urban Microclimate for SemiArid Climate (Constantine). Renewable Energy, v. 35, p. 343-347, 2010.
BRUSE, M.; FLEER, H. Simulating SurfacePlant-Air Interactions Inside Urban Environments With a Three-Dimensional Numerical Model.

Environmental Modelling \& Software, v. 13, n. 3-4, p. 373-384, oct. 1998.

BURTON, A.; BAMBRICK, H.; FRIEL, S. If You Don't Know How Can You Plan? Considering the health impacts of climate change in urban planning in Australia. Urban Climate, v. 12, p. 104-118, 2015.

\section{CENTRO DE PESQUISAS \\ METEOROLÓGICAS E CLIMÁTICAS \\ APLICADAS A AGRICULTURA. Clima de \\ Campinas. Disponível em: \\ $<$ http://www.cpa.unicamp.br/outras- informacoes/clima-de-campinas.html>. Acesso em: 9 maio 2016.}

CHOW, W. T. L.; BRAZEL A. J. Assessing Xeriscaping as a Sustainable Heat Island Mitigation Approach for a Desert City. Building and Environment, v. 47, p. 170-181, 2012.

DUARTE, D. H. S.; SERRA, G. G. Padrões de Ocupação do Solo e Microclimas Urbanos na Região de Clima Tropical Continental Brasileira: correlações e proposta de um indicador. Ambiente Construído, Porto Alegre, v. 3, n. 2, p. 7-20, abr./jun. 2003.

EMMANUEL, R.; JOHANSSON, E. Influence of Urban Morphology and Sea Breeze on Hot Humid Microclimate: the case of Colombo, Sri Lanka. Climate Research, v. 30, n. 3, p. 189-200, 2006.

EMMANUEL, R.; ROSENLUND, H.; JOHANSSON, E. Urban Shading: a design option for the tropics: a study in Colombo, Sri Lanka. International Journal of Climatology, v. 27, p. 1995-2004, 2007.

GOMES, P. S.; LAMBERTS, R. O Estudo do Clima Urbano e a Legislação Urbanística: considerações a partir do caso Montes Claros, MG. Ambiente Construído, Porto Alegre, v. 9, n. 1, p. 73-91, jan./mar. 2009.

GOOGLE EARTH. [Mapa]. Disponível em: $<$ https://www.google.com.br/intl/pt-PT/earth/>. Acesso em: 12 jan. 2017.

GUO, H.; MURRAY, F.; LEE, S. C. Emissions of Total Volatile Organic Compounds From Pressed Wood Products in an Environmental Chamber.

Building and Environment, v. 37, n. 11, p. 11171126, 2002. 
GUSSON, C. S. Efeito da Densidade Construída Sobre o Microclima Urbano: construção de diferentes cenários possíveis e seus efeitos no microclima para a cidade de São Paulo, SP. São Paulo, 2014. Dissertação (Mestrado em Arquitetura e Urbanismo) - Faculdade de Arquitetura e Urbanismo, Universidade de São Paulo, São Paulo, 2014.

HERRINGTON, L. P.; VITTUM, J. S. Human Thermal Comfort in Urban Outdoor Spaces. In: CONFERENCE ON METROPOLITAN PHYSICAL ENVIRONMENT, Syracuse, 1977. Proceedings... Syracuse, 1977.

HOPE, P. R. The Physiological Equivalent Temperature: a universal index for the assessment of the thermal environment. International Journal of Biometeorology, v. 43, p. 71-75, 1999.

INSTITUTO NACIONAL DE PESQUISAS ESPACIAIS. Dados Observacionais. 2017. Disponível em:

$<$ http://bancodedados.cptec.inpe.br/>. Acesso em: 12 jan. 2017.

JOHANSSON, E. Influence of Urban Geometry on Outdoor Thermal Comfort in a Hot Dry Climate: a study in Fez, Morocco. Building and Environment, v. 41, n. 10, p. 1326-1338, 2006.

JOHANSSON, E.; EMMANUEL, R. The Influence of Urban Design on Outdoor Thermal Comfort in the Hot, Humid City of Colombo, Sri Lanka. International Journal of Biometeorology, v. 51, n. 2, p. 119-133, 2006.

KLEEREKOPER, L.; VAN ESCH, M.; SALCEDO, T. B. How to Make a City ClimateProof, Addressing the Urban Heat Island Effect. Resources, Conservation and Recycling, v. 64, p. 30-38, 2012.

KRÜGER, E.; PEARLMUTTER, D.; RASIA, F. Evaluating the Impact of Canyon Geometry and Orientation on Cooling Loads in a High-Mass Building in a Hot Dry Environment. Applied Energy, v. 87, n. 6, p. 2068-2078, 2010.

MATZARAKIS, A.; RUTZ, F.; MAYER, H. Aplicativo computacional RayMan 1.2.

Disponível: <http://www.mif.uni-

freiburg.de/rayman/>. Acesso em: 9 dez. 2016.

MINELLA, F. C. O.; HONJO, S.; KRÜGER, E. L. Estratégias de Melhoria do Ambiente Térmico Diurno em Situação de Verão de Uma Fração Urbana da Cidade de São Paulo. Ambiente Construído, Porto Alegre, v. 12, n. 4, p. 139-158, out./dez. 2012.
MINELLA, F. C. O.; KRÜGER, E. L. Proposição do Índice “Fração Vegetada” e Sua Relação Com Alterações na Temperatura do Ar e no Conforto Térmico no Período Diurno e em Situação de Verão Para Curitiba. Ambiente Construído, Porto Alegre, v. 17, n. 1, p. 353-371, jan./mar. 2017.

MONTEIRO, L.; ALUCCI, M. Índices de Conforto Térmico em Espaços Urbanos Abertos. Fórum Patrimônio, Belo Horizonte, v. 4, n. 1, jan./jun. 2010.

MUNIZ, L. P.; PEZZUTO, C. C. O Efeito dos Parâmetros Urbanísticos na Variação Microclimática de Um Cânion Urbano. In: ENCONTRO NACIONAL DE TECNOLOGIA DO AMBIENTE CONSTRUÍDO, 16., São Paulo, 2016. Anais... Porto Alegre: ANTAC, 2016.

NAKATA-OSAKI, C. M.; SOUZA, L. C. L. de; RODRIGUES, D. S. Impacto da Geometria do Cânion Urbano na Intensidade de Ilha de Calor Noturna: análise através de um modelo simplificado adaptado a um SIG. Ambiente Construído, Porto Alegre, v. 16, n. 3, p. 73-87, jul./set. 2016.

NICHOLSON, S. E. A Pollution Model For streetLevel Air. Atmospheric Environment, v. 9, n. 1, p. 19-31, 1975.

OKE, T. R. Initial Guidance to Obtain Representative Meteorological Observations at Urban Sites. In: INSTRUMENTS and Observing Methods Report $n^{\circ}$ 81. WMO, 2006.

PEZZUTO, C. C. et al. Efeito da Vegetação na Variação da Temperatura Urbana em Diferentes Climas: estudo de caso na cidade de Campinas e Mendonza. In.: ENCONTRO NACIONAL, 13.; ENCONTRO LATINO-AMERICANO DE CONFORTO NO AMBIENTE CONSTRUÍDO, 9., Campinas, 2015. Anais... Campinas, 2015.

PREFEITURA MUNICIPAL CAMPINAS. Dados Geográficos. 2016. Disponível em:

<http://www.campinas.sp.gov.br/governo/seplama/ dados-do-municipio/cidade/> . Acesso em: 9 maio 2016.

PREFEITURA MUNICIPAL CAMPINAS. Lei $\mathbf{n}^{\mathbf{0}}$ 6.031 de 29 de dezembro de $\mathbf{1 9 8 8}$, atualizada em 2011, que dispõe sobre o Uso e Ocupação do Solo do município de Campinas, 2011.

SAILOR, D.; FAN, H. Modeling the Diurnal Variability of Effective Albedo For Cities. Atmosferic Environment, v. 36, p. 713-725, 2002. 
SHISHEGAR, N. Street Design and Urban Microclimate: analyzing the effects of street geometry and orientation on airflow and solar access in urban canyons. Journal of Clean Energy Technologies, v. 1, n. 1, 2013.

STONE, R. J. Improved Statistical Procedure for the Evaluation of Solar Radiation Estimation Models. Solar Energy, v. 51, n. 4, p. 289-291, 1993.

STRØMANN-ANDERSEN, J.; SATTRUP, P. A. The Urban Canyon and Building Energy Use: Urban density versus daylight and passive solar gains. Energy and Buildings, v. 43, n. 8, p. 20112020, ago. 2011.

VARDOULAKIS, S. et al. Modelling Air Quality in Street Canyons: a review. Atmospheric

Environment, v. 37, p. 155-182, 2003.
WILKS, D. S. Statistical Methods in the

Atmospheric Sciences. 2. ed. Academic Press, 2006. v. 91. International Geophysics Series.

WILLMOTT, C. J. On the Validation of Models, Physical Geography, v. 2, n. 2, p. 184-194, 1981.

YANG, X. et al. Evaluation of a Microclimate Model for Predicting the Thermal Behavior of Different Ground Surfaces. Building and

Environment, v. 60, p. 93-104, fev. 2013.

\section{Agradecimentos}

Os autores agradecem à Capes pela concessão de bolsa de mestrado.

\section{Lígia Parreira Muniz-Gäal}

Centro de Ciências Exatas, Ambientais e de Tecnologias, Programa de Pós-Graduação em Sistemas de Infraestutura Urbana | Pontifícia Universidade Católica de Campinas | Rodovia D Pedro I, Km 136, Parque das Universidades | Campinas - SP - Brasil | CEP 13086-900| Tel.: (19) 3343-7009 | E-mail: ligiapmuniz@gmail.com

\section{Cláudia Cotrim Pezzuto}

Centro de Ciências Exatas, Ambientais e de Tecnologias, Programa de Pós-Graduação em Sistemas de Infraestutura Urbana | Pontifícia Universidade Católica de Campinas | E-mail: claupezzuto@gmail.com

\section{Marcius Fabius Hemriques de Carvalho}

Centro de Ciências Exatas, Ambientais e de Tecnologias, Programa de Pós-Graduação em Sistemas de Infraestutura Urbana | Pontifícia Universidade Católica de Campinas | Tel.: (19) 3756-7370 | E-mail: marcius@puc-campinas.edu.br

\section{Lia Toledo Moreira Mota}

Laboratório de Instalações Elétricas, Centro de Ciências Exatas, Ambientais e de Tecnologias | Pontifícia Universidade Católica de Campinas | Tel.: (19) 3343-7009 | E-mail: lia.mota@puc-campinas.edu.br

\section{Revista Ambiente Construído}

Associação Nacional de Tecnologia do Ambiente Construído

Av. Osvaldo Aranha, 99 - 3o andar, Centro

Porto Alegre - RS - Brasil

CEP 90035-190

Telefone: +55 (51) 3308-4084

Fax: +55 (51) 3308-4054

www. seer. ufrgs. br/ ambienteconstruido

E-mail: ambienteconstruido@ufrgs.br

This is an open-access article distributed under the terms of the Creative Commons Attribution License. 